\title{
Preliminary non-invasive study of Roman glasses from Jesolo (Venice), Italy
}

\author{
Cristina Cherian, ${ }^{\mathrm{a}}$ Lavinia de Ferri, ${ }^{\mathrm{a} 1}$ Roberto Falcone, ${ }^{\mathrm{b}}$ Alessandra Cianciosi, ${ }^{\mathrm{c}}$ Sivia Cadamuro, ${ }^{\mathrm{c}}$ \\ Sauro Gelichic $\mathcal{E}$ Giulio Pojana ${ }^{\mathrm{a}}$ \\ a Department of Philosophy and Cultural Heritage, Ca'Foscari University, Venice, Italy \\ b Stazione Sperimentale del Vetro, Murano (Venice), Italy \\ ${ }^{\mathrm{c}}$ Department of Humanities, Ca'Foscari University, Venice, Italy
}

Manuscript received 25 May 2019

Revision received 11 December 2019

Manuscript accepted 16 December 2019

Archaeological excavations at 'Le Mure' site (Jesolo, VE, Italy) have followed each other since the sixties, when the first evidence of an Early Medieval church (6th-7th century AD) was found under the ruins of a Medieval Cathedral (11th-12th AD). The last few years of investigations by $C a^{\prime}$ Foscari University have led to the collection of large amounts of glass fragments, including many tesserae, dating between the 4 th and the 12th centuries AD. A selection of glass fragments and mosaic tesserae taken from the excavations performed in 2013-14 at this site were studied by means of reflectance spectroscopy in order to identify their chromophore ions, in particular $\mathrm{Cu}^{0}, \mathrm{Cu}^{2+}, \mathrm{Co}^{2+}, \mathrm{Fe}^{2+}$ and $\mathrm{Fe}^{3+}$, which were detected in both transparent and opaque samples. In addition, the use of high resolution close-up images allowed for the attribution of surface characteristics to specific manufacturing techniques, while glass chemistry was studied in order to group them into known compositional classes. This study, carried out by non-invasive analytical techniques that allowed for the acquisition of preliminary data, will prove useful in driving further methodologies involving other non-invasive and micro-invasive analysis in order to obtain archaeometric information that can be related to concurrent archaeological results.

\section{Introduction}

Many studies have been conducted on the chemical composition and structure of ancient and medieval glasses from Europe, Egypt and Asia see, e.g. Arletti et $a l^{(1)}$ and Lesigyarski et al. ${ }^{(2)}$ It is suggested that a manufacturing division existed during Roman Age production, since large amounts of glass were produced from alkali and sand in a limited number of primary workshops located in the Middle East, generally close to favoured source of these two main constituents. ${ }^{(2-4)}$ Here large glass slabs were cast and subsequently exported toward secondary sites closer to the point of their use for making finished products. ${ }^{(2-4)}$ This was mainly due to the exploitation of a limited number of sand deposits, lime, and flux as raw material sources in Egypt and in the Near East. ${ }^{(2-4)}$ In particular, archaeological Roman objects were mostly made using soda-lime-silica glass, with the sodabased flux obtained only a few times from vegetable or, more commonly, mineral sources. Specifically, natron was used and supplied by Egypt to other provinces of the Empire up until the 8th century AD, probably because of political events in the Nile Delta region. ${ }^{(2)}$ Natron quarries, including the well-known Wadi Natrun, were widely exploited from the early

\footnotetext{
${ }^{1}$ Corresponding authors. Email lavinia.deferri@unive.it or jp@unive.it DOI: 10.13036/17533546.61.1.003

Currently at: Norwegian University of Science and Technology, Department of Mechanical and Industrial Engineering, Trondheim, Norway.
}

4th millennium BC: they were generally considered to be evaporitic deposits of sodium carbonate and sodium bicarbonate even if, sensu stricto, natron is 10-hydrated sodium carbonate $\left(\mathrm{Na}_{2} \mathrm{CO}_{3} \cdot 10 \mathrm{H}_{2} \mathrm{O}\right)$, whereas the dominant phase in these deposits is frequently 2-hydrate sodium carbonate-bicarbonate, named trona $\left(\mathrm{Na}_{3}\left(\mathrm{CO}_{3}\right)\left(\mathrm{HCO}_{3}\right) \cdot 2 \mathrm{H}_{2} \mathrm{O}\right) \cdot{ }^{(5)}$

Consequently, European Roman and post-Empire glasses have developed a reputation for relatively constant compositions with $\mathrm{SiO}_{2}$ and $\mathrm{Na}_{2} \mathrm{O}$ as the main constituents, while small amounts of other minor components are characteristically present $\left(\mathrm{Al}_{2} \mathrm{O}_{3} \sim 2 \cdot 5\right.$ $\left.\mathrm{wt} \% ; \mathrm{CaO} \sim 6-8 \mathrm{wt} \% ; \mathrm{MgO} \leq 1.5 \mathrm{wt} \% ; \mathrm{K}_{2} \mathrm{O} \leq 1.5 \mathrm{wt} \%\right) .{ }^{(3,4)}$ These optimal proportions seem to have been discovered starting from the Hellenistic period, with small compositional variations observed during the following 800 years. This is due to the utilisation of the same initial raw material supply sites with some changes during 4 th -5 th centuries $\mathrm{AD}$ production, ${ }^{(4)}$ recently, studies focused on late Antique and early Medieval Italian glass demonstrated that several glass compositions, mainly based on the utilisation of natron as flux, coexisted starting from the 4 th -5 th centuries onwards, see e.g. Maltoni et al, ${ }^{(6)}$ Silvestri et $a l^{(7)}$ and Hellemans et al.$^{(8)}$ On the other hand, later specimens dated back to the 6th-7th centuries and until the 11th century were observed to have been produced from a different silica source ${ }^{(4)}$ or utilising vegetable ashes. ${ }^{(8,9)}$ 

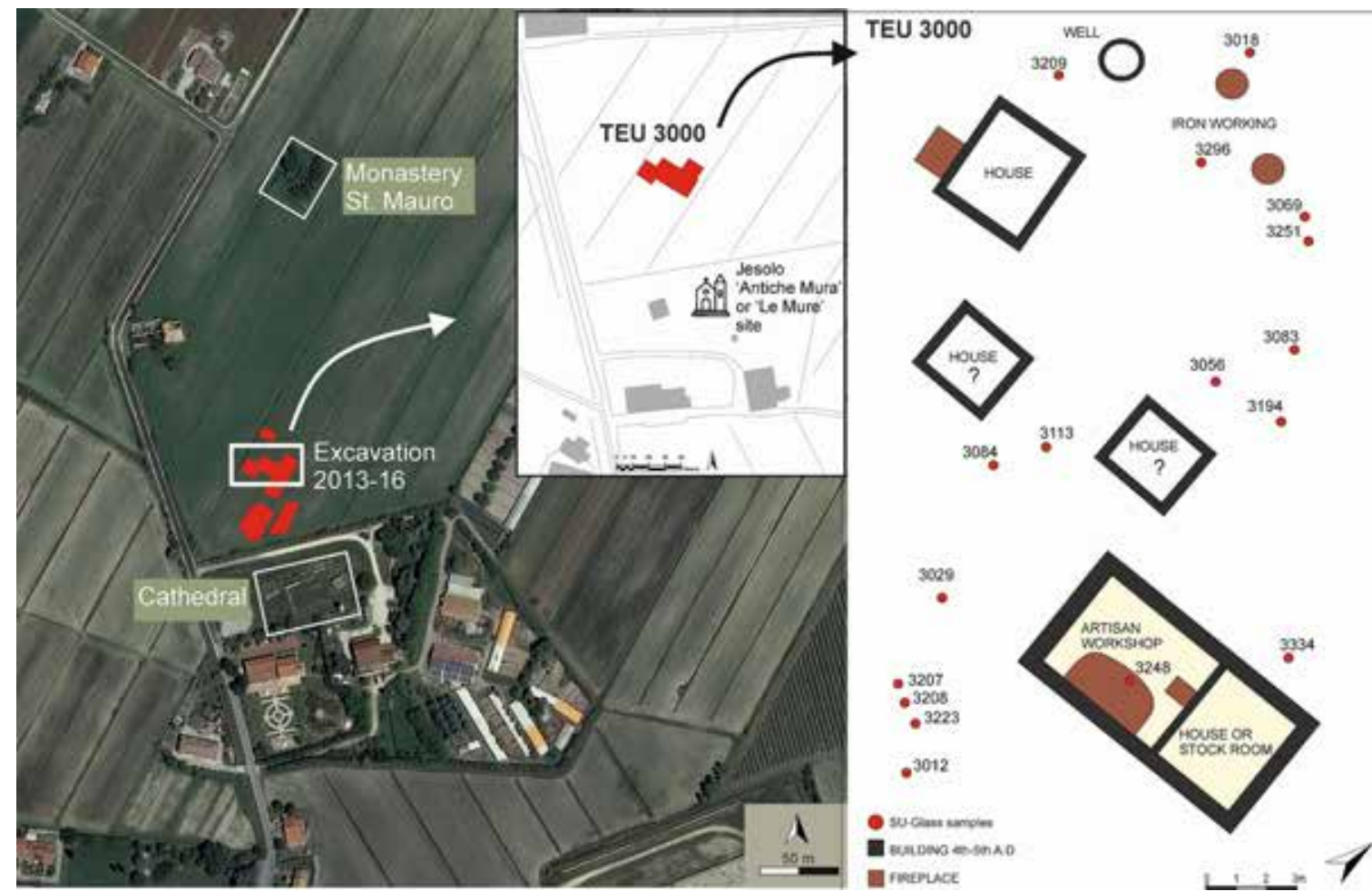

Figure 1. 'Antiche Mura' or 'Le Mure' (Jesolo, Venice, Italy) excavation site, with details of the main archaeological structures investigated in TEU 3000 and the position of SU of the glass samples [Colour available online]

This paper is concerned with the characterisation of glass fragments coming from the archaeological excavations carried out in Antiche Mura site (Jesolo, Venice, Italy) in 2013 and 2014. Many glass items, including tesserae, were found and a subset of them was investigated by utilising a non-invasive procedure.

\section{The Archaeological context}

The ancient town of Jesolo, called Equilus, was located in what is now the modern day north lagoon of Venice (Italy) and consisted of various religious buildings, churches and monasteries.

Nowadays, the remains of S. Maria Assunta Cathedral - dating back to the Romanesque period (11th12th centuries) and largely destroyed during the two World Wars - can be observed, as well as those of an early medieval church dating back to the mid 6th-7th centuries AD, located under the newer cathedral and discovered in the 1960s of the last century. In the 1980s, a Paleochristian church (5th century AD) was also identified under the aforementioned early medieval church. Thus, archaeological data describes the foundation of a complex and organised settlement, dating back to at least the 5th century AD.

During the last five years, new archaeological campaigns have been conducted by Ca' Foscari University of Venice, Department of Humanities, on the northern side of the ancient settlement, concerning the area reported in Figure 1. Many glass fragments were collected amongst the countless finds. Most findings could be traced back to fragments of com- mon use objects such as table and cooking ware, glasses, cups, lucernae (lamps), animal bones, shells, coins, buckles, and other small bronze and iron finds.

This work focuses on glass findings recovered during excavation campaigns carried out in 2013 and 2014 at the Antiche Mura site, covering a surface area of $250 \mathrm{~m}^{2}$ approx. $100 \mathrm{~m}$ far from the religious building previously described (Figure 1). Two trenches were taken into account and the study allowed for the identification of three archaeological periods ranging between the 1st century BC and the 6th century AD. The most ancient phase could be traced back to Roman period, between the 1st century BC and the 1 st century AD. The second period was dated back between the end of the 4 th and the beginning of the 5 th century AD, and the third period between the 6th and the 7th centuries AD. In the first epoch, a consistent deposit of Hexaplex Trunculus (murex) - exploited for the extraction of the so-called royal purple dye was also discovered. During the late Antiquity, many traces of the Equilus settlement were found: houses, warehouses, workshops (especially for iron and bone production), etc. Finally, the entire area was occupied by an early medieval cemetery (6th-7th centuries $\mathrm{AD})$, with the cemetarial area probably connected with the church mentioned above. ${ }^{(10)}$

Analysed samples come from the 3000 topographic excavation unit (TEU) and 17 stratigraphic units (SU, Figure 1), specifically from the campaign carried out in 2014, when remains of residential and commercial buildings dating back to the 5th century AD were discovered under the early medieval cemetery. 


\section{Materials and methods}

\subsection{The samples}

In this paper only samples found in the 3000 TEU, excavated during 2014, were considered.

In particular, 222 of 806 glass fragments, mainly referable to bottles, glass, cups and windows from the 4th-5th centuries AD (SU 3012, 3018, 3029, 3056, 3069, 3083, 3084, 3113, 3194, 3207, 3208, 3209, 3223, $3248,3251,3296,3334$, Figure 1) and related to residential and commercial buildings, were selected (HR images of all samples are available as Supplementary Material S1-S17 at the end of this paper). All samples were preliminarily cleaned using Milli $\rho$ water and neutral soap and then rinsed for $5 \mathrm{~min}$ in a $50 \mathrm{kHz}$ ultrasonic bath.

All 222 samples were documented through high resolution digital photography and analysed by fibre optics reflectance spectroscopy (FORS), while a restricted subset of five representative samples was also chemically analysed (see the following 3.2 section for details).

\subsection{Analytical techniques}

High resolution images were acquired under reflected and transmitted light by means of a D800E Nikon (Minato, Tokyo, Japan) digital camera and the Camera ControlPro2 dedicated software, working in live view mode. All pictures were recorded at 1:1 ratio $(3 \cdot 6 \times 2 \cdot 4$ $\mathrm{cm}$ area) coupling the camera with a Makro-Planar f/2.8 $100 \mathrm{~mm}$ lens by Zeiss (Oberkochen, Germany) fitted on a macro repro stand at ISO100, f8 aperture and shutter speed between $1 / 16$ and $1 / 2 \mathrm{~s}$. For thicker samples, an additional number of pictures were taken at various focal planes, depending on their size and geometry, and merged to extend optical depth of field through the Zerene Stacker (Zerene Systems LLC, Richland, WA, USA) software.

Findings were also illuminated with a $365 \mathrm{~nm}$ ultraviolet LED lamp (Madatec, Pessano a Bornago, Italy) to evaluate the occurrence of luminescent phenomena.
Reflectance spectra were collected using a Quest $U$ by B\&W Tek Inc. (Newark, DE, USA) portable fibre optic spectrophotometer, connected to a tungsten light source through a $Y$ shaped silica glass fibre bundle, which is composed of seven fibres $(\varnothing=200$ $\mu \mathrm{m}$ each) entering a SMA 905 model reflection probe with a $4 \mathrm{~mm}^{2}$ collecting spot; six fibres illuminated the sample and one collected the signal. Light is guided and focused on an aligned and optically matched slit ( $25 \mu \mathrm{m}$, leading to an optical resolution of approx. $1.5 \mathrm{~nm}$ ). A system of focusing $\mathrm{AlMg}_{2}$ coated mirrors allows for the collimation and redirection of the light beam toward the grating and then to a refocusing mirror addressing the light to a 2048 pixel linear silicon CCD array detector.

Spectra were collected in the $370-950 \mathrm{~nm}$ interval and a $99 \%$ Teflon-based diffuse reflectance metrological standard from Labsphere (North Sutton, $\mathrm{NH}$, US) was used for calibration after a dark acquisition. Every spectrum was taken averaging 128 cycles of 50 $\mathrm{ms}$ each to enhance signal/noise ratio while keeping both incident and acquisition angles at $45^{\circ}$ from the surface normal, in order to not include the specular reflection component. The spectrometer was connected to a PC via a USB port and was managed by means of the BWSpec4 (by B\&W Tek) dedicated software for spectra acquisition and colorimetric data collection.

Scanning electron images were acquired using a field emission gun-equipped EISS Sigma VP microscope, with a detection area of $10 \mathrm{~mm}^{2}$, primary beam energy $20 \mathrm{keV}$, acquisition time of $150 \mathrm{~s}$ and $20 \mathrm{~mm}$ working distance.

The chemistry of a selected subset of five samples (Tables 1,2), chosen from the three of most representative SUs of the time periods of interest (Late Antiquity), was also investigated. Due to restrictions that did not allow the sampling, a completely non-invasive approach was followed. Analyses were carried out by means of an energy dispersive $x$-ray micro-fluorescence spectrometry $(\mu E D-X R F)$ using a Bruker (Billerica, MA, USA) M4 Tornado spectrom-

Table 1. Summary table of the analysed samples

\begin{tabular}{|c|c|c|c|c|}
\hline Sample & $\begin{array}{l}\text { Stratigraphic } \\
\text { unit }\end{array}$ & Colour & Aspect & Bubbles \\
\hline O9 & 3208 & green opaque & $\begin{array}{l}\text { Opaque glass tessera. Rough surface. } \\
\text { After washing open pores still contain deposited } \\
\text { material }\end{array}$ & $\begin{array}{l}\text { Many, small, round and of similar } \\
\text { dimension }\end{array}$ \\
\hline A3 & 3069 & red opaque & $\begin{array}{l}\text { Opaque glass tessera. Smooth and glossy surface. } \\
\text { After washing open pores still contain deposited } \\
\text { material }\end{array}$ & $\begin{array}{l}\text { Many, small, round and of different } \\
\text { dimension }\end{array}$ \\
\hline E8-decoration & 3084 & blue transparent & Glass drops. Smooth surface. & $\begin{array}{l}\text { Many, small, round and of different } \\
\text { dimension }\end{array}$ \\
\hline E8-bulk & 3084 & green transparent & $\begin{array}{l}\text { Smooth surfaces with many scratches. The external } \\
\text { side is rougher than the internal one. }\end{array}$ & $\begin{array}{l}\text { Few, small, round, homogeneously } \\
\text { distributed. }\end{array}$ \\
\hline F7-decoration & 3084 & white opaque & Surface decoration. Linear, opaque, rough & Undetectable \\
\hline F7-bulk & 3084 & light blue transparent & $\begin{array}{l}\text { Smooth surface on the internal side, very } \\
\text { rough surface on the external one. }\end{array}$ & $\begin{array}{l}\text { Many, elonged and with the same } \\
\text { orientation, different dimensions }\end{array}$ \\
\hline R4 & 3207 & blue transparent & The external side is rougher than the internal one. & $\begin{array}{l}\text { Few, small, round, homogeneously } \\
\text { distributed. }\end{array}$ \\
\hline
\end{tabular}


Table 2. Chemical composition ( $w t \%$ ) of the selected samples

\begin{tabular}{|c|c|c|c|c|c|c|c|}
\hline & $\begin{array}{l}\text { E8 Blue } \\
\text { decoration }\end{array}$ & $\begin{array}{l}\text { E8 Green } \\
\text { bulk }\end{array}$ & $\begin{array}{l}\text { F7 White } \\
\text { decoration }\end{array}$ & F7 Colourless & $\begin{array}{l}\text { R4 Blue } \\
\text { bulk }\end{array}$ & A3 Red & O9 Green \\
\hline $\mathrm{SiO}_{2}$ & $65 \cdot 6$ & $76 \cdot 0$ & $69 \cdot 7$ & $72 \cdot 2$ & $78 \cdot 5$ & $69 \cdot 8$ & $36 \cdot 8$ \\
\hline $\mathrm{TiO}_{2}$ & $0 \cdot 26$ & $0 \cdot 28$ & $0 \cdot 15$ & $0 \cdot 13$ & $0 \cdot 16$ & $0 \cdot 11$ & $0 \cdot 30$ \\
\hline $\mathrm{Al}_{2} \mathrm{O}_{3}$ & $2 \cdot 8$ & $2 \cdot 9$ & $2 \cdot 9$ & $3 \cdot 3$ & $2 \cdot 6$ & $2 \cdot 8$ & $3 \cdot 7$ \\
\hline $\mathrm{CaO}$ & $6 \cdot 0$ & $6 \cdot 4$ & $8 \cdot 0$ & $8 \cdot 8$ & $7 \cdot 5$ & $6 \cdot 8$ & $9 \cdot 4$ \\
\hline $\mathrm{MgO}$ & $0 \cdot 7$ & $0 \cdot 7$ & $1 \cdot 3$ & 0.5 & $0 \cdot 4$ & $0 \cdot 6$ & $0 \cdot 5$ \\
\hline $\mathrm{Na}_{2} \mathrm{O}$ & $13 \cdot 5$ & $9 \cdot 7$ & $11 \cdot 2$ & $12 \cdot 0$ & $8 \cdot 5$ & $10 \cdot 1$ & $5 \cdot 7$ \\
\hline $\mathrm{K}_{2} \mathrm{O}$ & $0 \cdot 7$ & $0 \cdot 6$ & $1 \cdot 2$ & $1 \cdot 6$ & $1 \cdot 0$ & $0 \cdot 8$ & $1 \cdot 2$ \\
\hline $\mathrm{Fe}_{2} \mathrm{O}_{3}$ & $4 \cdot 1$ & $1 \cdot 2$ & $1 \cdot 0$ & $0 \cdot 7$ & $1 \cdot 0$ & $6 \cdot 0$ & 1.9 \\
\hline $\mathrm{MnO}$ & 1.9 & $2 \cdot 1$ & $0 \cdot 4$ & $0 \cdot 3$ & $0 \cdot 1$ & $1 \cdot 0$ & $1 \cdot 1$ \\
\hline $\mathrm{Sb}_{2} \mathrm{O}_{5}$ & n.d. & n.d. & $3 \cdot 2$ & n.d. & n.d. & $0 \cdot 3$ & $3 \cdot 8$ \\
\hline $\mathrm{PbO}$ & $2 \cdot 8$ & n.d. & $0 \cdot 5$ & $0 \cdot 3$ & n.d. & $0 \cdot 4$ & $24 \cdot 8$ \\
\hline $\mathrm{CuO}$ & $1 \cdot 1$ & n.d. & $0 \cdot 10$ & 0.07 & 0.07 & $1 \cdot 1$ & $8 \cdot 3$ \\
\hline $\mathrm{CoO}$ & $0 \cdot 23$ & n.d. & n.d. & n.d. & 0.06 & n.d. & n.d. \\
\hline $\mathrm{NiO}$ & $0 \cdot 02$ & n.d. & n.d. & n.d. & 0.01 & n.d. & n.d. \\
\hline $\mathrm{SnO}_{2}$ & $0 \cdot 1$ & n.d. & $0 \cdot 2$ & n.d. & n.d. & $0 \cdot 1$ & 1.9 \\
\hline $\mathrm{SrO}$ & $0 \cdot 11$ & $0 \cdot 08$ & $0 \cdot 11$ & $0 \cdot 08$ & 0.07 & $0 \cdot 08$ & $0 \cdot 40$ \\
\hline $\mathrm{ZrO}_{2}$ & $0 \cdot 05$ & n.d. & n.d. & n.d. & n.d. & n.d. & $0 \cdot 18$ \\
\hline Total & 99.95 & 99.96 & 99.96 & 99.98 & 99.96 & 99.99 & 99.98 \\
\hline
\end{tabular}

eter operating at $40 \mathrm{kV}, 700 \mathrm{~mA}, 28 \mathrm{~W}, 100 \mathrm{~s}$ real time counting times. Analyses were performed without any sample preparation on original weathered surfaces. Several points (spot diameter: approx. 30 $\mu \mathrm{m})$ were analysed on each sample and mean values were calculated in order to evaluate the homogeneity of the surfaces. Concentrations determined by the fundamental parameters method after deconvolution of acquired spectra were corrected using A, B, C and D Corning glasses as reference materials. ${ }^{(11)}$ The analytical precision, measured as the relative standard deviation, ranged between 0.5 and $1 \%$ for main components and between 1 and $10 \%$ for minor and trace components. $\mathrm{TiO}_{2}, \mathrm{MnO}$ and $\mathrm{Fe}_{2} \mathrm{O}_{3}$ data have been recalculated for plotting on a ternary diagram.

\section{Discussion of results}

\subsection{High resolution imaging, close-up photography and scanning electron microscopy}

The studied samples exhibited different states of conservation which are well documented thanks to the use of close-up photography. Detailed, high magnification images were useful in identifying surface differences in terms of the extent of surface patinas. In particular, growths of typical iridescent patina displayed on the stems of cups; these commonly occur on buried glass objects due to the growth of laminar structures, both on surfaces and into tubular cavities of their bases (Figure 2(a),(b)). These surface layers were also found to flake off as shown in Figure 2(c). Further characteristic alteration structures such as dendritic patterns were identified in a few of the samples (Figure 2(d)): previous studies ${ }^{(12)}$ clearly showed that they are linked to Mn ions intrusion from the environment into leached glass, whose lower density allows higher ionic mobility compared to pristine glass. This permits the formations of such dark brownish areas, also enriched in $\mathrm{Fe}, \mathrm{Ca}$ and $\mathrm{P}$. In particular, Schalm et al, ${ }^{(12)}$ stated that $\mathrm{Mn}^{2+}$ ions undergo an oxidation process to $\mathrm{Mn}^{4+}$, which is the $\mathrm{Mn}$ form found in the inclusions despite the very low solubility of its oxides and hydroxides in aqueous solutions (present in the burial environment) and its absence in the glass structure.

Furthermore, the presence of peculiar red signs was noticed on the decorated stains of cup fragments (Figure 2(e)): two very thin red lines were found under the blue drops, likely made before sticking
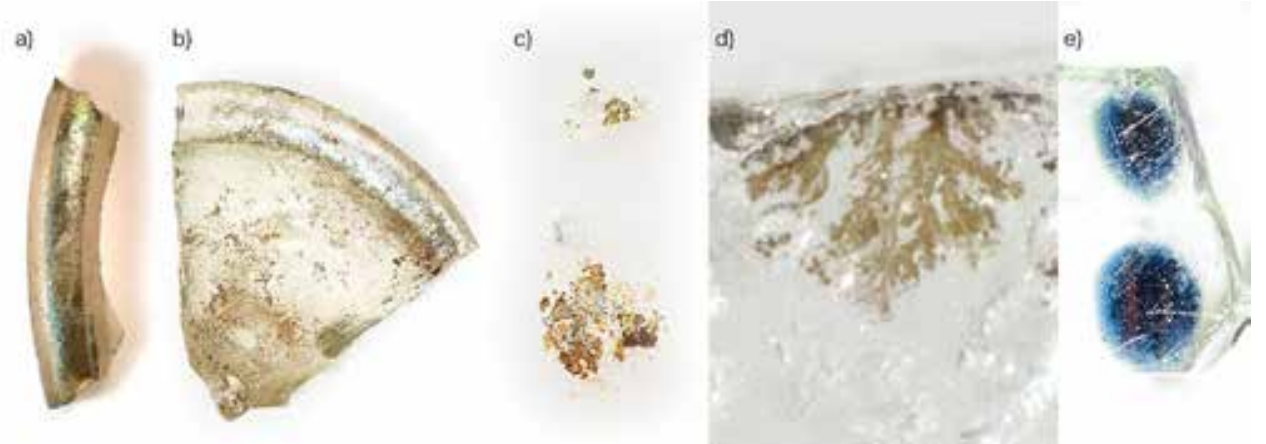

Figure 2. (a), (b) Samples G8 from SU 3084 and A8 from SU 3194 with typical iridescent patina; (c) flaked off patina from A8 sample; (d) dendritic structures in V1 sample from SU 3207; (e) detail of red signs on E8 from SU 3084 [Colour available online] 


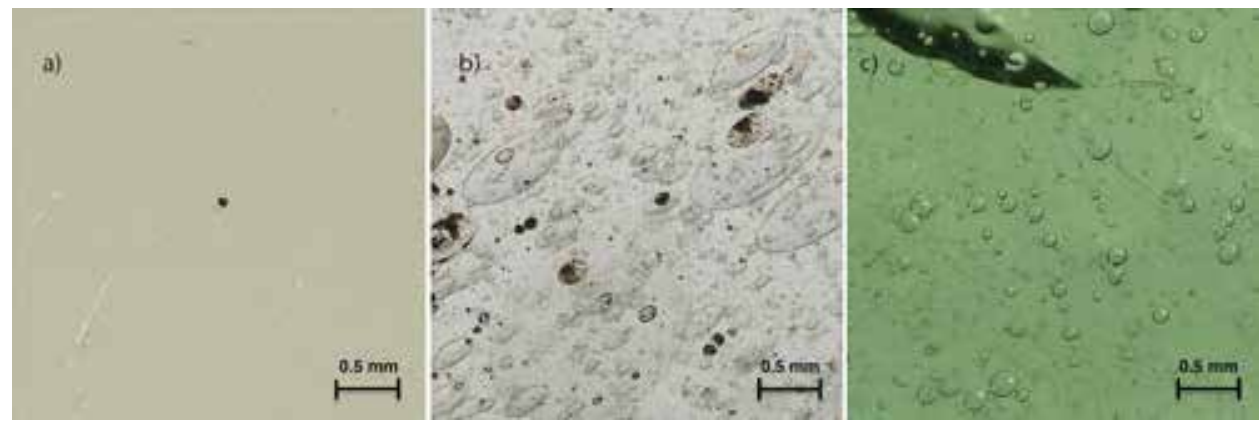

Figure 3. (a) bubble-free N5 sample from SU 3334; (b) V1 sample from SU 3207, elongated bubbles; (c) Q1 sample from SU 3207- round bubbles [Colour available online]

them to the surface of the green cup in order to create references for the correct alignment of decorations.

High resolution images were also used to evaluate the shape and distribution of trapped air bubbles. This last characteristic is useful in formulating hypotheses about the production techniques utilised, since the presence of elongated bubbles can be ascribed to the blowing technique, ${ }^{(1)}$ while round shaped ones can be traced back to the casting on moulds (Figure 3 (a)-(c)). Of the 222 fragments that were examined, 52 samples contain bubbles: the bubbles are elongated in 37 of them, spherical in eight pieces, while the remaining exhibit mixed shapes.

In a few cases findings showed a strong green fluorescence when lighted up at $365 \mathrm{~nm}$ and preliminary laser induced fluorescence (LIF) measurements showed luminescence maxima $\left(\lambda_{\mathrm{ex}}=375 \mathrm{~nm}\right)$ at about 530 and $660 \mathrm{~nm}$. This band combination strongly resembles the luminescence spectra of glasses containing $\mathrm{Mn}^{2+}$ in tetrahedral and octahedral sites ${ }^{(13,14)}$ (Figure S18).

Different surface conservation states were also checked by means of electron microscopy, leading to observations of clear differences in terms of surface corrosion. As shown in Figure 4(a) and 4(b), the O9 green tessera was much more deteriorated in comparison to the red A3 sample, with its entire surface covered by pitting phenomena. In contrast, the round cavities on the A3 surface are due to open bubbles. At the same time, the surfaces of samples that were apparently in a good state of conservation revealed cracks in some areas when observed by electron microscopy (Figure 4(c)).

\subsection{Fibre optic reflectance spectroscopy (FORS)}

Many applications of reflectance spectroscopy to historical glasses can be found in literature, ${ }^{(13-22)}$ even though this technique is predominantly employed for painted surfaces. One of the first studies focused on the glassy blue pigment smalt; ${ }^{(16)}$ this study of the $\mathrm{Co}^{2+}$ environment was fundamental in understanding the reasons for the pigment fading. Subsequently, this analytical method has been widely used for the identification of chromophores since it allows their discrimination without any sampling. ${ }^{(15,17,23)}$ Fibre optic reflectance spectroscopy (FORS) is, in fact, a cheap and versatile tool that permits the preliminary discriminative analysis of artwork colours, deriving from the introduction of small amounts of transition metal ions in specific oxidation states to the moulding batch. ${ }^{(22)}$ In addition, artisans would have been able to obtain a wide range of shades by expertly modifying furnace atmospheres, temperatures and/ or the addition of other elements.

Most glass colours can indeed be explained by the ligand field theory, which predicts various absorption band positions for a given matrix as they are closely related to glass composition. ${ }^{(19,22,24)}$ The investigated samples displayed a limited number of colours: with the exception of some colourless fragments and two tesserae (a red and a green one), only green, light blue, dark blue and a few brownish pieces were found. Representative spectra are reported in Figure 5. In

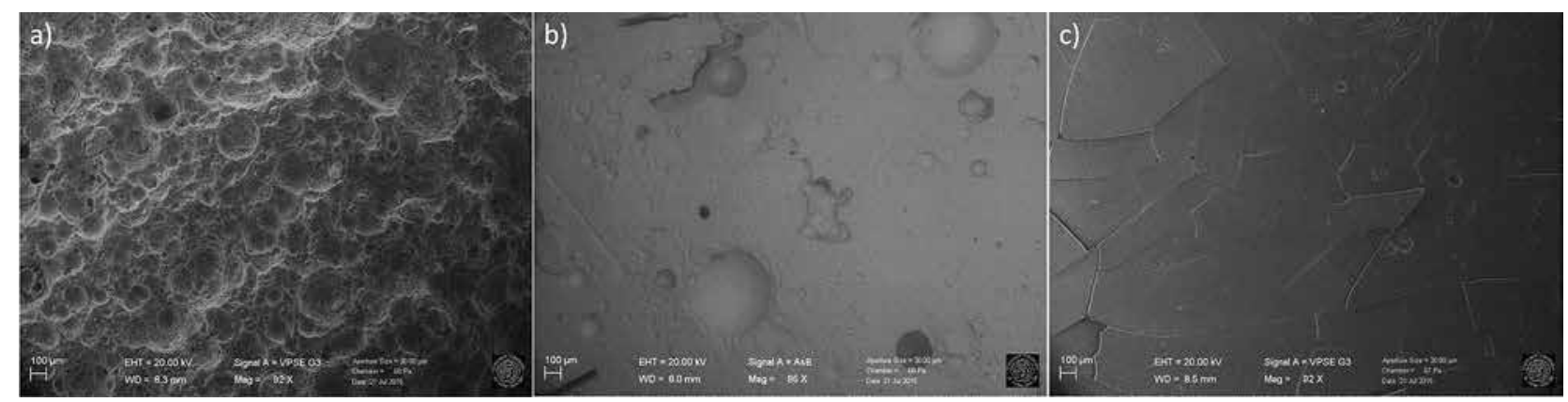

Figure 4. Secondary electron images of (a) O9, opaque green tessera from SU 3208; (b) A3 opaque red tessera from SU 3069; (c) R15 from SU 3012 

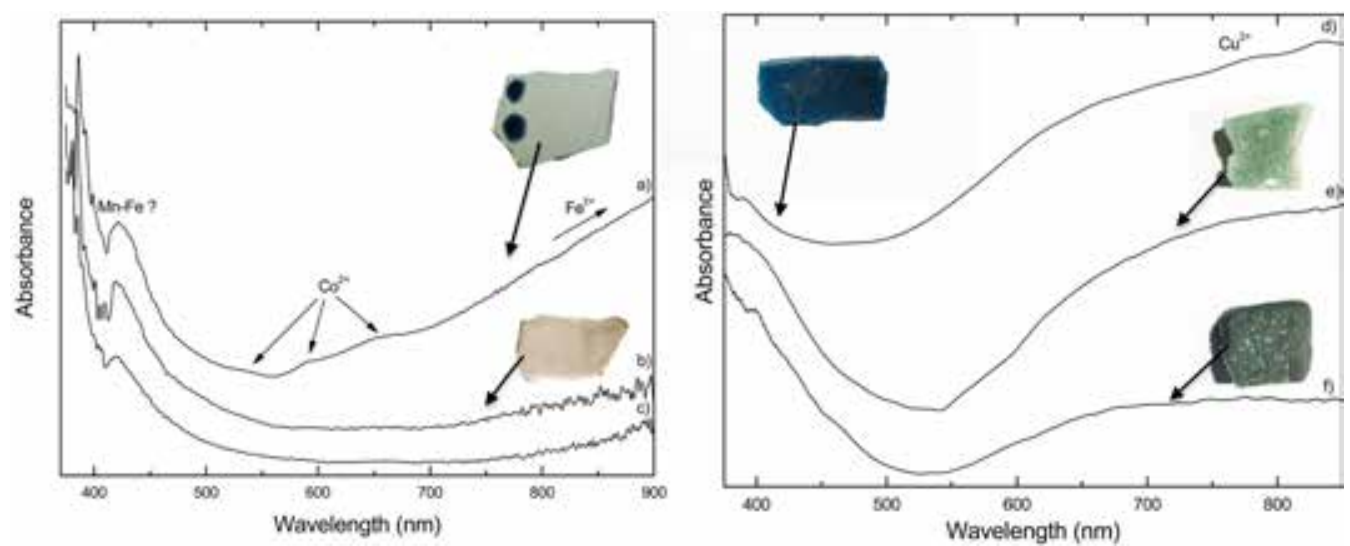

Figure 5. Absorption spectra of (a) E8 from SU 3804; (b) C8 from SU 3521; (c) C9 from SU 3521; (d) R5 from SU 3207 ; (e) B3 from SU 3069; (f) O9 from SU 3208 [Colour available online]

many cases the identified features are attributable to the presence of iron in the glass matrix, which produces hues ranging from blue to green, black, or yellow-brown as a result of different concentrations and relative proportions of $\mathrm{Fe}^{2+}$ and $\mathrm{Fe}^{3+}$ ions, sometimes also accompanied by the presence of sulphur in the glass melt. ${ }^{(22)}$ Consequently, glass fragments containing the same total amount of iron can show different hues, indicating that they were produced in different ways. ${ }^{(22,24)}$ Generally, $\mathrm{Fe}^{3+}$ ion displays strong absorption in the ultraviolet spectral range while the absorptions falling in the VIS interval $(380,420$, $440 \mathrm{~nm}$ ) exhibit much lower intensities, providing a yellowish colour to the glass. On the other hand, the $\mathrm{Fe}^{2+}$ ion main absorption band maximum fall in the NIR range and only its tail can be detected when working in the VIS spectral interval. This leads to a bluish colour of the final glass, while other colours are generated by the simultaneous presence of both ions in various relative proportions. ${ }^{(19)}$

Reflectance spectroscopy can therefore be considered a useful tool to achieve information about ions relative proportions and consequently about the applied melting temperatures or the prevalent redox conditions (air atmosphere, and melting time). ${ }^{(19,22,24)}$ The $\mathrm{Fe}^{2+}\left(\mathrm{d}^{6}\right)$ ion is barely detectable by the instrument available (working in the 370-916 nm spectral range) since its main feature is an absorbance band at about 1050-1100 nm due to a $d d$ spin-allowed ${ }^{5} \mathrm{~T}_{2} \rightarrow{ }^{5} \mathrm{E}$ ion transition in the octahedral coordination; ${ }^{(14,22)}$ the band broadness is due to the Jahn-Teller distortion of the octahedrally coordinated metal. ${ }^{(22)}$ Its presence can only be hypothesised by considering the increasing absorbance of the spectra toward longer wavelengths. This could be the case in samples E8, C8 and C9 (Figure 5(a)-(c)), the first also showing small amounts of $\mathrm{Co}^{2+}$ not revealed by chemical analysis (see section 4.3 and Table 2). In addition, a relatively intense feature can be observed at about $420 \mathrm{~nm}$, close to a very noisy spectral area; this could be interpreted as the result of $\mathrm{Mn}-\mathrm{Fe}$ complexes, as reported by Meulebroeck et $a l_{,}^{(24)}$ formed due to re- ducing conditions during glass production. Analysis by XRF confirms the presence of high amounts of Mn in E8 (Table 2) but no data regarding the two other samples are available.

$\mathrm{Fe}^{2+}\left(\mathrm{d}^{5}\right)$ ions indicate reducing conditions during glass production, while $\mathrm{Fe}^{3+}$ ions suggest the utilisation of an oxidising atmosphere. As known, for $\mathrm{Fe}^{3+}$ as well for all $\mathrm{d}^{5}$ ions energy diagrams for tetrahedral and octahedral coordination are identical. Anyway, the tetrahedral coordination of $\mathrm{Fe}^{3+}$ is generally much more common for soda-lime-silica glasses. ${ }^{(22)}$ $\mathrm{Fe}^{3+}$ features are recorded as low intensity signals, as usually occurs for $d d$ transitions, in several blue samples containing $\mathrm{Co}^{2+}$ (Figure 6). The first absorption peak, normally the most intense one, due to the $d d$ spin forbidden ${ }^{6} \mathrm{~A}_{1} \rightarrow{ }^{4} \mathrm{E}$ transition, is barely visible, as it is located at the beginning of the instrumental spectral range; in contrast, two small peaks can be

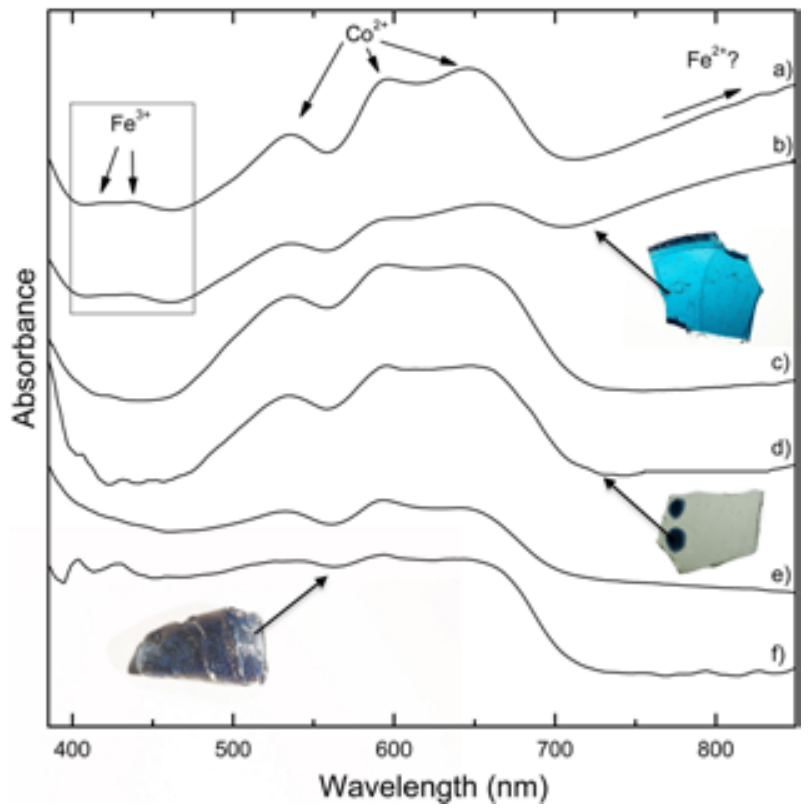

Figure 6. Absorption spectra of (a) R4 from SU 3207; (b) R6 from SU 3207; (c) T14 from SU 3012; (d) E8 from SU 3804; (e) D7 from SU 3251; (f) B12 from SU 3018 [Colour available online] 
easily observed at about 415 and $440 \mathrm{~nm}$, produced by two other $d d$ spin forbidden transitions: ${ }^{6} \mathrm{~A}_{1} \rightarrow{ }^{4} \mathrm{~T}_{2}$ and ${ }^{6} \mathrm{~A}_{1} \rightarrow{ }^{4} \mathrm{~A}_{1},{ }^{4} \mathrm{E} \cdot{ }^{(14)} \mathrm{In}$ addition, Fe ions can also lead to charge transfer $(\mathrm{CT})$ phenomena between the two ions when occurring simultaneously, a quite common condition for glasses where ratios between $\mathrm{Fe}^{2+}$ and $\mathrm{Fe}^{3+}$ ions are due to both melting conditions and chemistry. Unfortunately, the induced CT band occurs at shorter wavelength values with respect to the investigable interval. ${ }^{(22)}$

Copper was also detected in many blue and green fragments (Figure 5(d)-(e)): its presence is typically evidenced by a large broad band located between $\sim 750$ and $870 \mathrm{~nm}$ attributed to the ${ }^{2} \mathrm{E}_{\mathrm{g}} \rightarrow{ }^{2} \mathrm{~T}_{2 \mathrm{~g}}$ transition of the octahedral complex, split into sub-bands mainly due to distortions of the site along the $z$-axis. The ${ }^{2} \mathrm{~B}_{1 \mathrm{~g}} \rightarrow{ }^{2} \mathrm{~A}_{1 \mathrm{~g}},{ }^{2} \mathrm{~B}_{1 \mathrm{~g}} \rightarrow{ }^{2} \mathrm{~B}_{2 \mathrm{~g}}$ and ${ }^{2} \mathrm{~B}_{1 \mathrm{~g}} \rightarrow{ }^{2} \mathrm{E}_{\mathrm{g}}$ transitions in turn produce bands partially superimposing generating the broad and asymmetric band usually detected. ${ }^{(22)}$ The band centroid is influenced by the composition of the glass matrix, moving toward longer wavelengths with decreasing ligand field strength (i.e. substitution of $\mathrm{Na}^{+}$with $\left.\mathrm{K}^{+}\right) .{ }^{(15)} \mathrm{Cu}^{2+}\left(\mathrm{d}^{9}\right)$ was probably employed as colorant for the opaque green O9 tessera, as well as in B3 and in the blue R5 fragments. The colour difference depends on the coordination of $\mathrm{Cu}$ ions, with penta- and exa-coordination leading to green and blue colours, respectively, while its lower colouring power with respect to $\mathrm{Co}^{2+}$ (see below) is attributable to the lower extinction coefficient of $\mathrm{Cu}$ as well as to the partial reduction to $\mathrm{Cu}^{+}\left(\mathrm{d}^{1} 0\right)$, for which $d d$ transitions cannot occur, being the $d$ orbital fully occupied. ${ }^{(22)}$

Most of blue samples are coloured by means of $\mathrm{Co}^{2+}\left(\mathrm{d}^{7}\right)$ which, due to its particularly high colouring power (molar extinction coefficient $\xi_{590}=200 \mathrm{~L} /$ mol cm${ }^{-1}$ ), could be added in very low quantities to glass and is thus not always chemically detectable. The $\mathrm{Co}^{2+}$ spectra in the VIS range are characterised by various absorption bands due to $d d$ transitions: this ion is predominantly tetra-coordinated but can occur also in octahedral and cubic symmetries. ${ }^{(16,21)}$ As known, ${ }^{(16,18,21,25)}$ the spectrum of $\mathrm{Co}^{2+}$ consists of three main bands located in the visible and infrared region: they are indicated as $v_{1}, v_{2}$ and $v_{3}$, and are all due to ligand field $d d$ electronic transitions. ${ }^{(16)}$ The $v_{3}$ is the only band investigable in this study since it falls in the VIS spectral region and, as well as $v_{2}$, it splits into three sub-bands because of distortions exhibited by the tetrahedral site. ${ }^{(16,21)}$ Variation in $\mathrm{Co}^{2+}$ band positions as a function of glass chemistry has been extensively studied in recent years, ${ }^{(16,20,21)}$ revealing shifting relatable, e.g. to different fluxes introduced in the batch. ${ }^{(16,18,21)}$ In particular, the position of the central VIS sub band resulted to be affected in potash-lime-silica and soda-lime-silica glass, since it shifts from $\sim 526 \mathrm{~nm}$ to $\sim 535 \mathrm{~nm} .{ }^{(18)}$ In the investigated fragments the observed absorption features perfectly

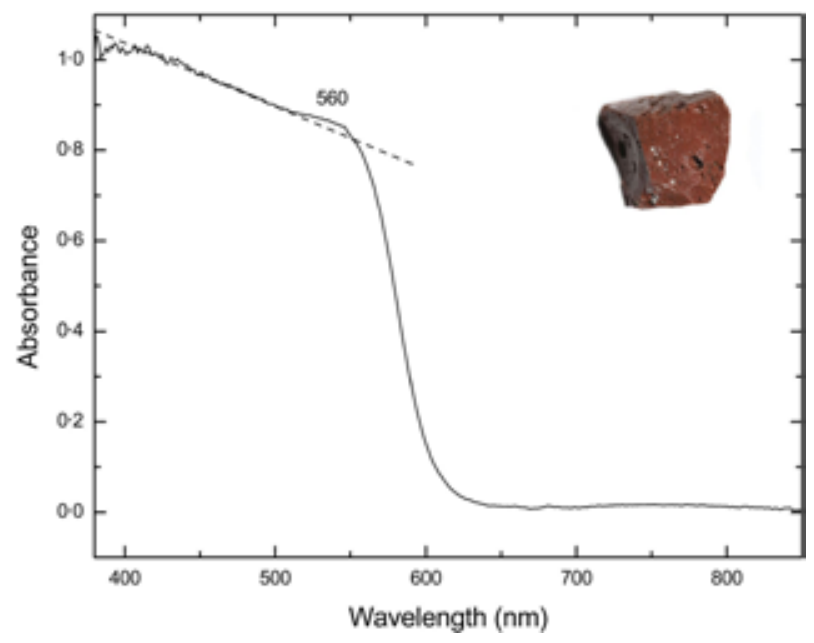

Figure 7. Absorbance spectrum of A3 from SU 3069 [Colour available online]

match the maxima positions reported in literature for $\mathrm{Co}^{2+}$ in tetrahedral coordination in soda-lime-silica glasses ${ }^{(15,16,18,21)}$ with the spin-allowed ${ }^{4} \mathrm{~A}_{2}(\mathrm{~F}) \rightarrow{ }^{4} \mathrm{~T}_{1}(\mathrm{P})$ transition at $590 \mathrm{~nm}$, the spin-forbidden (very close in energy transition $)^{4} \mathrm{~A}_{2}(\mathrm{~F}) \rightarrow{ }^{2} \mathrm{~T}_{1}(\mathrm{G})$ and ${ }^{4} \mathrm{~A}_{2}(\mathrm{~F}) \rightarrow{ }^{2} \mathrm{E}(\mathrm{G})$ at $\sim 535 \mathrm{~nm}$, and the spin-forbidden transition ${ }^{4} \mathrm{~A}_{2}(\mathrm{~F})$ $\rightarrow{ }^{2} \mathrm{~T}_{2}(\mathrm{G})$ at $640 \mathrm{~nm}$, respectively. ${ }^{(25)}$

Blue glass fragments displayed, in fact, band positions between 533 and $535 \mathrm{~nm}$ (Figure 6), consistent with those reported for soda-lime-silica glass, as is expected of Roman samples.

Finally, the red mosaic tessera A3 spectrum disshows the typical $\mathrm{S}$ shape of red glasses, associated with a very small feature at about $560 \mathrm{~nm}$ due to a surface plasmon resonance effect which suggests the presence of nanosized $\mathrm{Cu}^{0}$ crystals (Figure 7). ${ }^{(26)}$ Despite the very high concentration of iron (Table 2) the absorbance spectrum does not display any spectral features of Fe-bearing phases, suggesting that $\mathrm{Cu}^{0}$ is the main colouring agent, acting thanks to light scattering phenomena, in spite of its relatively low concentration in the matrix (Table 2).

\subsection{Chemical analysis}

As already indicated in section 3.2, the chemistry of only five samples could be investigated working in a non-invasive way. Obtained data mostly refer to fragment surfaces that, as shown in section 4.1 displayed different degrees of alteration due to burial conditions. This limitation was taken into account in conclusions drawn by the following discussion. Chosen samples were considered representative of classes of fragments in order to support archaeologists in decisions concerning further micro-invasive analysis for future researches.

Compositional data for major elements are reported in Table 2 and clearly show, notwithstanding their altered surfaces, that four analysed samples are soda-lime-silica glasses, as expected for typical 
Roman productions, while the O9 tessera results in a lead-rich matrix. Taking into account the first fragments, $\mathrm{SiO}_{2}, \mathrm{CaO}$ and $\mathrm{Na}_{2} \mathrm{O}$ concentrations fall in the $\sim 65-78 \mathrm{wt} \%, 6-8 \cdot 8 \mathrm{wt} \%$, and $8.5-13.5 \mathrm{wt} \%$ ranges, respectively; the alumina content also remains relatively constant, varying between 2.8 and $3.7 \mathrm{wt} \%$, consistent with feldspars belonging to sand employed as a raw material. ${ }^{(36)}$ Despite the surface nature of the analysis, our data indicate that $\mathrm{CaO}$ amounts are consistent with those generally found in Roman glasses made by traditional methods, while $\mathrm{Na}_{2} \mathrm{O}$ amounts look lower than the usual ( 15-20 wt\%) quantities. This can be clearly attributed to leaching processes occurring during burial.

Investigation of lime and alumina concentrations was widely utilised for studying the sources of glass sand $^{(3)}$ since they reflect their typical impurities (calcite, feldspar and clay minerals). Detected quantities of $\mathrm{CaO}$ and $\mathrm{Al}_{2} \mathrm{O}_{3}$ are plotted in Figure 8(a), also reporting the characteristic ranges of the four principal compositional groups: Levantine I and II, European Roman glass and Egypt II. ${ }^{(27)}$

From Figure 8(a), it is evident that fragments from Jesolo site fall into the Levantine I group, except for $\mathrm{O}$, which $\mathrm{Al}_{2} \mathrm{O}_{3}$ content is higher than other samples and outside any group. These groups were defined by Freestone et $a l^{(3)}$ studying samples of Palestinian production. Levantine I class includes glass produced between the 4th and the 7th centuries AD from Byzantine workshops of Apollonia, Bet Shean, and Dor, as well as from late Roman workshops of Jalame (all located in current Israel),with the latter likely using sand from the Belus River. ${ }^{(28)}$ The presence of these workshops on the Levantine coast was supported by ancient authors such as Pliny the Elder and Strabo, and many excavations revealed large, primary glassmaking workshops distributing glass chunks to secondary facilities where final objects were created. For this reason, the composition of many findings can be traced back to primary productions areas. ${ }^{(28)}$

In the last years, another approach for discriminating within various sand sources was followed, involving the evaluation of ratios between different couples of oxides such as $\mathrm{Fe}_{2} \mathrm{O}_{3} / \mathrm{TiO}_{2}$ versus $\mathrm{Fe}_{2} \mathrm{O}_{3} /$ $\mathrm{Al}_{2} \mathrm{O}_{3}, \mathrm{Fe}_{2} \mathrm{O}_{3} / \mathrm{TiO}_{2}$ versus $\mathrm{Fe}_{2} \mathrm{O}_{3} / \mathrm{TiO}_{2}$ and $\mathrm{TiO}_{2} / \mathrm{Al}_{2} \mathrm{O}_{3}$

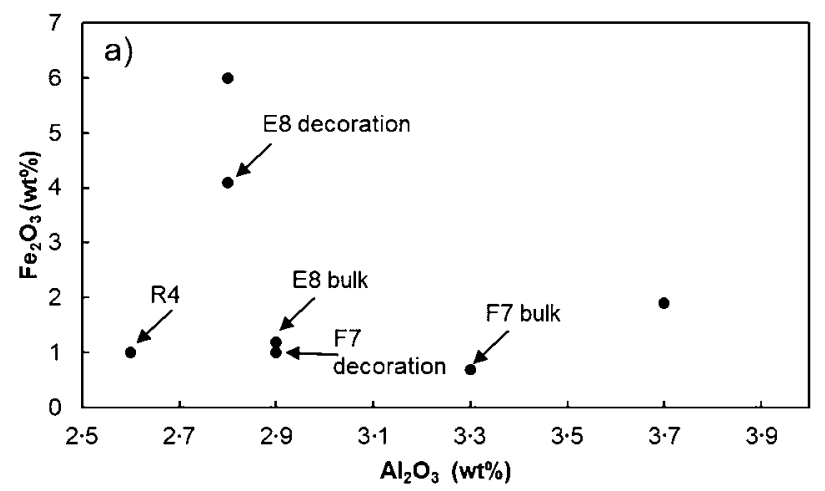

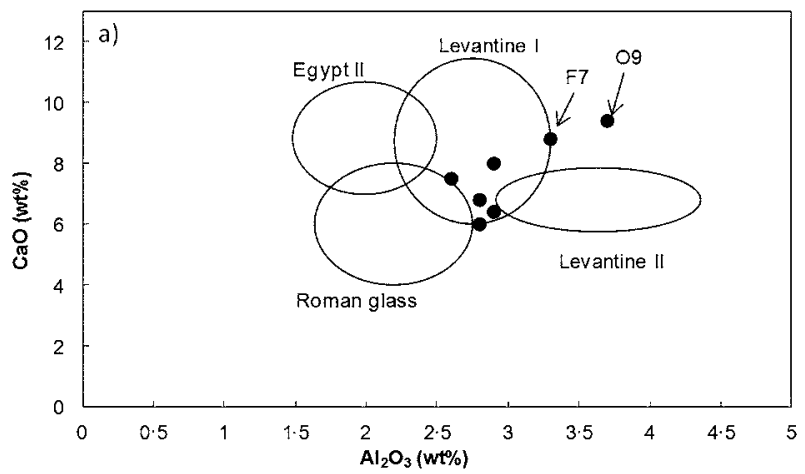

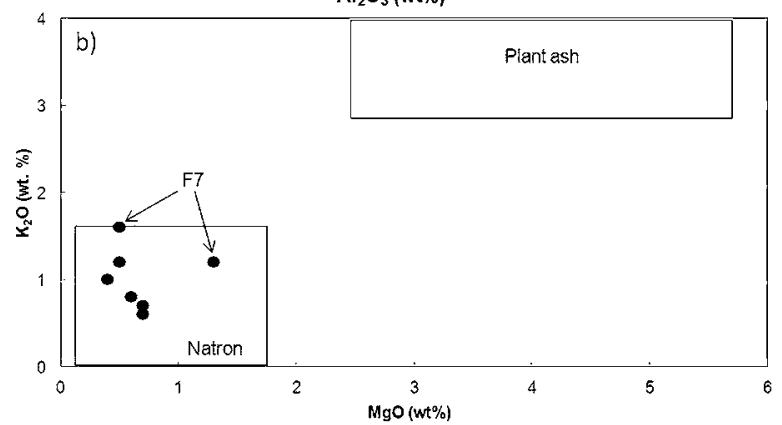

Figure 8. Plots of (a) CaO versus $\mathrm{Al}_{2} \mathrm{O}_{3}(w t \%)$ and (b) $\mathrm{K}_{2} \mathrm{O}$ versus $\mathrm{MgO}(w t \%)$, for analysed samples

versus $\mathrm{Al}_{2} \mathrm{O}_{3} / \mathrm{SiO}_{2}$, good geochemical markers for sand. ${ }^{(29)}$ Interestingly, the relation between $\mathrm{Fe}_{2} \mathrm{O}_{3} /$ $\mathrm{Al}_{2} \mathrm{O}_{3}$ (Figure 9(a)) evidenced how the bulk and decoration of sample E8 fall into two well separated regions indicated as HIMTa and HIMTb in literature studies, ${ }^{(29)}$ even if the bulk seems to be located very close to the border with the area related to Levantine I compositions. The belonging to this last class seems to be confirmed for F7 (both the bulk and the decoration) and R4.

When taking into account the amount of $\mathrm{TiO}_{2}$ (Figure 9(b)), only the E8 bulk falls into the HIMTa group while the decoration resulted to be completely out of the ranges $\left(\mathrm{Fe}_{2} \mathrm{O}_{3} / \mathrm{TiO}_{2} \sim 15 \cdot 8 ; \mathrm{Fe}_{2} \mathrm{O}_{3} / \mathrm{Al}_{2} \mathrm{O}_{3} \sim 1 \cdot 46\right)$; the same applies to F7 sample, whose bulk resulted well matching the Levantine I group while the decoration seems to fall into the HLIMT (high lime iron manganese and titanium) group, as well as R4, notwithstanding the $\mathrm{MnO}$ concentration of 0.4 and $0 \cdot 1 \mathrm{wt} \%$, respectively. ${ }^{(29)}$ Such incongruities can be probably attributed to the surface character of the

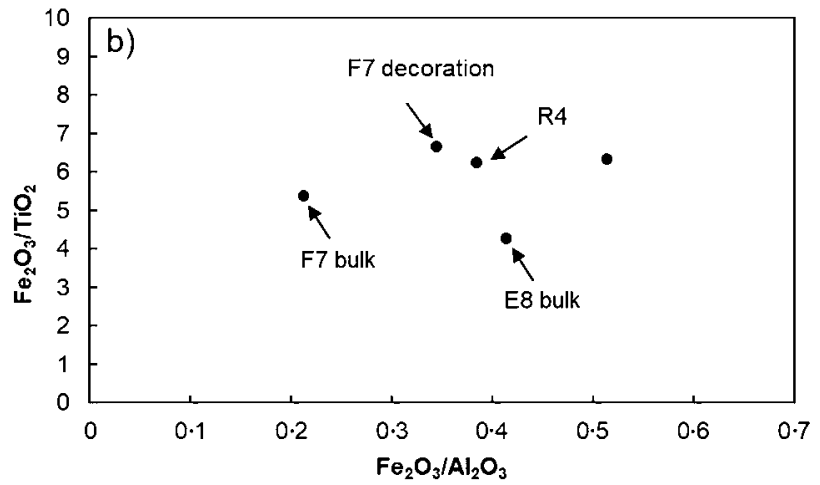

Figure 9. Plots of (a) $\mathrm{Fe}_{2} \mathrm{O}_{3}$ versus $\mathrm{Al}_{2} \mathrm{O}_{3}$ (wt\%) and (b) $\mathrm{Fe}_{2} \mathrm{O}_{3} / \mathrm{TiO}_{2}$ versus $\mathrm{Fe}_{2} \mathrm{O}_{3} / \mathrm{Al}_{2} \mathrm{O}_{3}$ 
performed chemical analysis.

This grouping is consistent with the analysed samples even when taking into account the $\mathrm{Sr}$ concentrations, which are higher than $0.04 \mathrm{wt} \%{ }^{(27)}$ while $\mathrm{Na}_{2} \mathrm{O}$ values are probably affected by depletion occurred during burial. The same applies to $\mathrm{Sr}$ content,(0.07-0.08 wt $\%)$ associated with extremely low $\mathrm{ZrO}$ quantities, such that it could not be determined throughout the employed instrument for most samples: this is any way consistent with the use of coastal sands, such those typically employed in the 5th century AD. ${ }^{(1,30)}$ Exceptions are represented by $\mathrm{O} 9$ and by the blue decorative drops on E8: in both cases, $\mathrm{SrO}$ and $\mathrm{ZrO}$ amounts are quite high, indicating that continental sands were likely employed instead. ${ }^{(3,6,31)}$ Such hypothesis is strengthened by differences in terms of Ti, Mn and Fe concentrations (Figure 10(a)). As already displayed in Figure 9(a), the results seem to be consistent with values attributable to the HIMT (high iron manganese titanium) class, widespread between the 4 th-5th centuries $\mathrm{AD}^{(14)}$ when radical changes occurred in glass manufacturing. This kind of glass was initially recognised by Freestone when studying raw glass chunks from Carthage, ${ }^{(32)}$ and then many other authors identified samples displaying HIMT compositions at various sites, confirming that it was widely traded, especially in the western Mediterranean. . $1,3,4,28,33,34)$ These findings were likely produced with new local silica sources, rich in heavy metals, ${ }^{(1,4)}$ due to changes in the political economy within the north-western Roman provinces. ${ }^{(1,14)}$ The HIMT glass typically show a yellow-green hue due to higher levels of iron within impure sands, while the relatively high concentrations of manganese $(\sim 2 \mathrm{wt} \%$ in E8), due to the intentional addition of pyrolusite $\left(\mathrm{MnO}_{2}\right)$ aimed to eliminate the yellow-green colour ${ }^{(37)}$ thanks to the redox equilibrium between $\mathrm{Fe}^{2+}$ (blue), $\mathrm{Fe}^{3+}$ (yellow), $\mathrm{Mn}^{3+}$ (pink) and $\mathrm{Mn}^{2+}$ (colourless) generated in the glass. ${ }^{(14,24)}$

Differences in $\mathrm{TiO}_{2}$ and $\mathrm{MnO}$ concentrations were also used to estimate production dates, since 1st-2nd century AD findings typically contain low $\mathrm{TiO}_{2}$ quantities; on the other hand, samples from the 4th century are instead characterised by higher concentrations of both elements (Figure 10(b)). ${ }^{(35,36)}$ As a result, given that all archaeological information date all analysed samples to the 4 th-5th centuries $\mathrm{AD}$, fragments F7, A3 and R4 are suggested to be instead from the 1st2nd centuries AD. The possibility of being recycled glass fragments, a well-known habit especially for mosaic tesserae (like A3), or the possibility of residual glass fragments in the layers of other samples, should also be considered.

Considerations like those previously discussed for $\mathrm{CaO}$ and $\mathrm{Na}_{2} \mathrm{O}$ can also be applied to $\mathrm{MgO}$ and $\mathrm{K}_{2} \mathrm{O}$ quantities; the former is found to be within the expected range, while the latter is found to be slightly higher than those reported in the literature. ${ }^{(37)}$
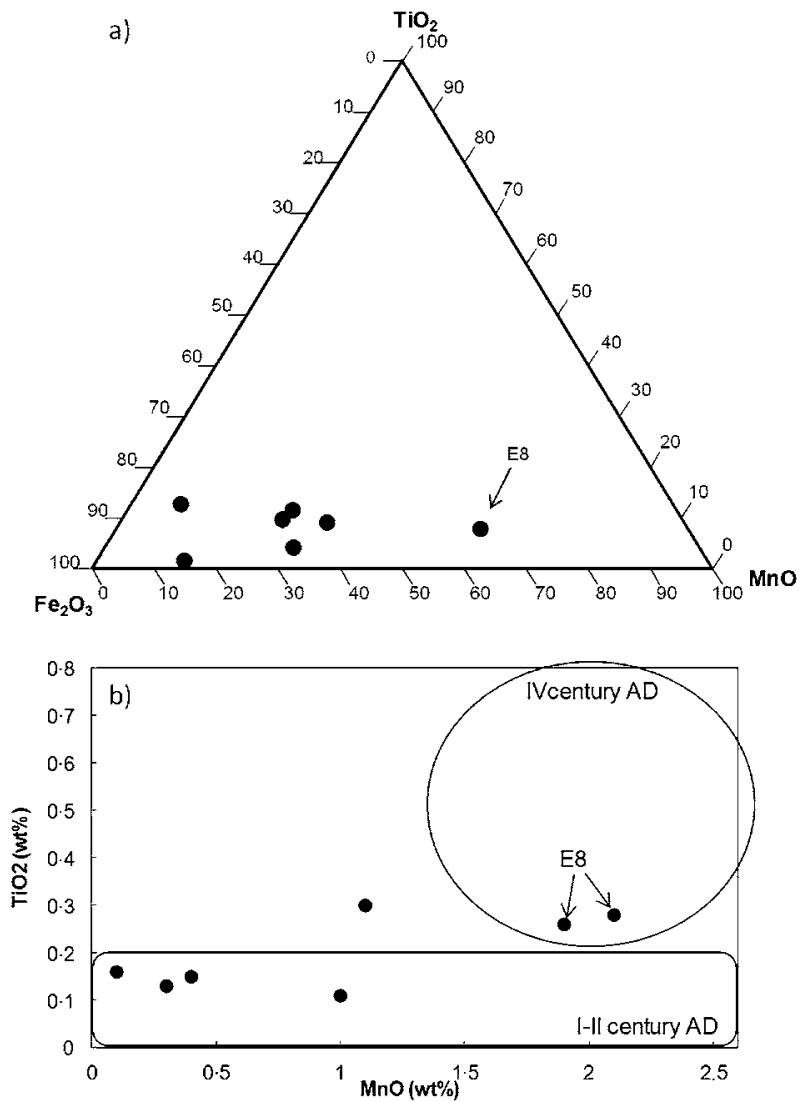

Figure 10. (a) Ternary plot: $\mathrm{TiO}_{2}-\mathrm{MnO}-\mathrm{Fe}_{2} \mathrm{O}_{3}$ (recalculated $w t \%$ ) for analysed samples; (b) plot of $\mathrm{CaO}$ versus $\mathrm{Al}_{2} \mathrm{O}_{3}(w t \%)$ for analysed samples

In any case, concentrations lower than $1.6 \mathrm{wt} \%$ for both oxides indicate that all samples were produced using natron as flux, ${ }^{(1,38)}$ as typically found for Roman and Byzantine glass. The content of the two oxides in the investigated samples is plotted in Figure 8(b) and compared with values previously found by Lilyquist \& Brill for natron-based and plant ash-based glass fragments. ${ }^{(38)}$ Two points, both corresponding to F7 sample, fall close to the limits of the natron glass area. The highest potash concentration of this sample could indicate impurities in the raw sand. At the same time, a higher $\mathrm{MgO}$ value in the white decoration would indicate the use of Mg-bearing minerals in the opaque mixture.

Finally, the SbO concentration was also evaluated, and was found to be $>1$ (wt \%) in both O9 and the F7 white decorations, with the latter associated with relatively high concentrations of $\mathrm{CaO}$, leading to the conclusion that $\mathrm{Ca}$ antimonate was used as opacifier to realise this detail. ${ }^{(36)}$

Among the selected samples, two opaque tesserae were analysed: opaque glass was produced from the middle of the 2nd millennium BC to the middle of Roman Imperial period ( 2 nd century AD) in many shades of yellow, blue, green, and red, as well as white. Several studies have focused on opaque glass in order to identify colouring, opacifying agents and their production techniques. ${ }^{(39)}$ 
As indicated in section 4.2 , the deep red hue in A3 was attributed to presence of $\mathrm{Cu}^{0}$. The chemical composition of the tessera was compared with results reported in literature for red opaque glass fragments and some evidence was found for Byzantine samples from Beit Shean (Israel) as investigated by Sughar ${ }^{(40)}$ containing relatively high iron oxide and relatively low copper oxide contents of up to $7 \mathrm{wt} \%$ and $\sim 1.54$ $w t \%$, respectively. The hypothesis formulated in section 4.2 for the origin of the red colour is also supported by the studies of Padovani et al, who demonstrated that the chromatic effect is determined only by the fraction of $\mathrm{Cu}$ ions reduced to metal $\mathrm{Cu}^{0}$ nanoparticles. ${ }^{(41)}$

The green 09 tessera displays very low concentrations $(\sim 37 \mathrm{wt} \%)$ of silica, compared to very high contents ( $25 \mathrm{wt} \%)$ of $\mathrm{PbO}$. The presence of high quantities of lead in mosaic glass is not uncommon, since when in the form of $\mathrm{Pb}_{2} \mathrm{Sb}_{2} \mathrm{O}_{7}$ it generates a typical opaque yellow colour which can create green shades if combined with copper or cobalt. ${ }^{(39,42)}$ In the first case, the lead amount generally exceeds the stoichiometric requirements for antimonate generation, allowing some lead to remain freely dispersed in the glass matrix. ${ }^{(43,44)}$ The relatively high $\mathrm{PbO}$ content of $\mathrm{O} 9$ has similarities in yellow and green mosaic tesserae from Roman villae in Tusa and Taormina (Messina, Sicily, Italy), dating back between the $3 \mathrm{rd}$ and the 4 th centuries AD and to the 2 nd century AD, respectively. ${ }^{(45)}$ In those cases, the authors interpreted such samples as having been derived from the periodic re-use of pre-existing waste glass.

The green tessera from Jesolo excavation shows also a significant concentration of $\mathrm{Sb}_{2} \mathrm{O}_{5}$ (Table 2), which is consistent with the formation of lead antimonate, visible on the tessera surface as small yellow grains. The relatively high $(8 \cdot 3 \mathrm{wt} \%) \mathrm{CuO}$ content can account for the overall green colour.

The recycling of glass waste or bronze flakes was a common practice in Roman times since it permitted to lower the working temperature and/or to obtain several shades of green hues due to the introduction of copper. ${ }^{(8)}$ The relative proportions of some elements such as $\mathrm{Pb}, \mathrm{Cu}$ and $\mathrm{Sn}$ can be used in order to distinguish recycled glassy materials, ${ }^{(8)}$ generally displaying concentrations higher than 90, 200 and $100 \mathrm{ppm}$, respectively. ${ }^{(8,34)} \mathrm{The} \mathrm{Pb}, \mathrm{Cu}$ and $\mathrm{Sn}$ values (50479, 230222 and 66305 ppm) obtained for O9 are abundantly greater that those indicated by Foy et $a l,{ }^{(34)}$ supporting the hypothesis that the tessera could be derived from recycled material and in particular from the remains of a glassy paste used for ceramic enamels, reused and cut in form of tesserae. ${ }^{(46)}$

\section{Conclusions}

The possibility of applying non-invasive techniques to the investigation of archaeological glasses was exploited and was found to be suitable in the gathering of useful data while avoiding sample damage.

Close-up digital photography allowed for the identification of specific surface features that could be attributed to the main manufacturing methods, while FORS supplied exhaustive information about chromophores, allowing the detection of $\mathrm{Co}^{2+}, \mathrm{Fe}^{3+}$, $\mathrm{Fe}^{2+}, \mathrm{Cu}^{2+}$ and $\mathrm{Cu}^{0}$.

Chemical data from XRF measurements, even though obtained using a non-invasive approach and consequently providing only surface information, were enough to identify the main raw materials employed in their production and to suggest probable dates for the analysed findings. Determined concentrations of $\mathrm{Ti}, \mathrm{Al}$ and $\mathrm{Sr}$ lead to the hypothesis that coastal sands were used, with the exception of the E8 sample, whose body was produced with continental sands and belonged to the HIMT class.

For all investigated glass samples a sodic evaporitic flux was employed, and comparisons with literature data allowed to group them into the Levantine I class, with the exception of the O9 green tessera, which was particularly enriched in $\mathrm{PbO}$. Both its shape and chemical composition suggest the recycling of glassy materials originally used for ceramic enamels.

\section{Acknowledgements}

Authors gratefully acknowledge the financial support of Madatec srl (Pessano con Bornago, MI, Italy) to the present investigation and for providing the employed instrumentation.

Authors are also very grateful to D. Vallotto (Ca' Foscari University of Venice, Italy) for its support during acquisition and elaboration of photographic images.

\section{References}

1. Arletti, R., Vezzalini, G., Benati, S., Mazzeo Saracino, L. \& Gamberini, A. Roman window glass: a comparison of findings from three different Italian sites. Archaeometry, 2010, 52, 252-71.

2. Lesigyarski, D., Šmit, Ž., Zlateva-Rangelova, B., Koseva, K. \& Kuleff, I. Characterisation of the chemical composition of archaeological glass finds from South-Eastern Bulgaria using PIXE, PIGE and ICP-AES. J. Radioanal. Nucl. Chem., 2013, 295, 1605-19.

3. Freestone, I. C., Gorin-Rosen, Y. \& Hughes, M. J. Primary glass from Israel and the production of glass in Late Antiquity and the Early Islamic Period. La Route du verre. Ateliers primaires et secondaires $d u$ second millénaire av. J.-C. au Moyen Âge. Travaux de la Maison de l'Orient méditerranéen, 2000, 33, 65-83.

4. Aerts, A., Velde, B., Janssens, K. \& Dijkman, W. Change in silica sources in Roman and post-Roman glass. Spectrochim. Acta B, 2003, 58, 659-67.

5. Shortland. A. J., Schachter, L., Freestone, I. C. \& Tite, M. Natron as a flux in the early vitreous materials industry: sources, beginnings and reasons for decline. J. Archaeol. Sci, 2006, 33, 521-30.

6. Maltoni. S., Silvestri. A., Marcante. A. \& Molin. G. The transition from roman to late Antique glass: new insights from the domus of Tito Macro in Aquileia (Italy). J. Archaeol. Sci., 2016, 73, 1-16.

7. Silvestri, A., Dotsika, E., Longinelli, A., Selmo, E. \& Doukata-Demertzi, S. Chemical and oxygen isotopic composition of Roman and late antique glass from northern Greece. J. Chem., 2017, 2017, 1-14.

8. Hellemans, K., Cagno, S., Bogana, L., Janssens, K. \& Mendera, M. LAICP-MS labels early medieval Tuscan finds from Siena and Donoratico 
as late natron glass. J. Archaeol. Sci. Rep., 2019, 23, 844-53

9. Cagno, S., Favaretto, L., Mendera, M., Izmer, A., Vanhaecke, F. \& Janssens, K. Evidence of early medieval vegetable-ash glass in the archaeological site of San Genesio (Tuscany). J. Archaeol. Sci., 2012, 39, 1540-52.

10. Cadamuro, S., Cianciosi, A. \& Negrelli, C. The Insula Equilus: A Lagoon Community in the Early Middle Ages. Venice and Its Neighbors from the 8th to 11th Century. Brill, 2017, Chapt. 5, 90-115.

11. Wagner, B., Nowak, A., Bulska, E., Hametner, K. \& Günth, D. Critical assessment of the elemental composition of Corning archeological reference glasses by LA-ICP-MS. Anal. Bioanal. Chem., 2012, 402, 1667-77.

12. Schalm, O., Proost, K., De Vis, K., Cagno, S., Janssens, K., Mees, F., Jacobs, P. \& Caen, J. Manganese staining of archaeological glass: the characterisation of Mn-rich inclusions in leached layers and a hypothesis of its formation. Archaeometry, 2011, 53, 103-122.

13. Ehrt, D. Photoluminescence in glasses and glass ceramics. IOP Conf. Ser. Mater. Sci. Eng. 2009, 2, 012001-1-012001-7.

14. de Ferri, L., Arletti, R., Ponterini, G. \& Quartieri, S. XANES, UV-VIS and luminescence spectroscopic study of chromophores in ancient HIMT glass. Euro. J. Mineral., 2011, 23, 969-80.

15. Bacci, M., Corallini, A., Orlando, A., Picollo, M. \& Radicati, B. The ancientstained windows by Nicolò di Pietro Gerini in Florence. A noveldiagnostic tool for non-invasive in situ diagnosis. J. Cult. Herit., 2007, 8, 235-41.

16. Bacci, M., Picollo, M. Non-destructive spectroscopic detection of cobalt(ii) in paintings and glass. Stud. Conserv., 1996, 41, 136-44.

17. Borgia, I., Brunetti, B., Mariani, I., Sgamellotti, A., Cariati, F., Fermo, P., Mellini, M., Viti, C. \& Padeletti, G. Heterogeneous distribution of metal nanocrystals in glazes of historical pottery. Appl. Surf. Sci., 2002, 185, 206-16.

18. Ceglia, A., Meulebroeck, W., Baert, K., Wouters, H., Nys, K., Thienpont, H. \& Terryn, H. Cobalt absorption bands for the differentiation of historical $\mathrm{Na}$ and $\mathrm{Ca} / \mathrm{K}$ rich glass. Surf. Interf. Anal. 2012, 44, 219-26.

19. Ceglia, A., Nuyts, G., Meulebroeck, W., Cagno, S., Silvestri, A., Zoleo, A., Nys, K., Janssen, K., Thienpont, H. \& Terryn, H. Iron speciation in soda-lime-silica glass: a comparison of XANES and UV-vis-NIR spectroscopy. J. Anal. Atom. Spectrom., 2015, 30, 1552-61.

20. Fornacelli, C., Colomban, Ph. \& Turbanti Memmi, I. Toward a Raman/ FORS discrimination between Art Nouveau and contemporary stained glasses from $\mathrm{CdS}_{\mathrm{x}} \mathrm{Se}_{1-\mathrm{x}}$ nanoparticles signatures. J. Raman Spectrosc., 2015, 46, 1129-39.

21. Fornacelli, C., Ceglia, A., Bracci, S. \& Vilarigues, M. The role of different network modifying cations on the speciation of the $\mathrm{Co}^{2+}$ complex in silicates and implication in the investigation of historical glasses. Spectrochim. Acta A, 2018, 188, 507-15.

22. Möncke, D., Papageorgiou, M.,Winterstein-Beckmann, A. \& Zacharias,
N. Roman glasses coloured by dissolved transition metal ions: redox ,reactions, optical spectroscopy and ligand field theory. J. Archaeol. Sci., 2014, 46, 23-36.

23. Arletti, R., Conte, S., Vandini, M., Fiori, C., Bracci, S., Bacci, M. \& Porcinai, S. Florence baptistery: chemical and mineralogical investigation of glass mosaic tesserae. J. Archaeol. Sci., 2011, 38, 79-88.

24. Meulebroeck, W., Baert, K., Wouters, H., Cosyns, P., Ceglia, A., Cagno. S., Janssens, K., Nys, K., Terryn, H. \& Thienpont, H. The identification of chromophores in ancient glass by the use of UV-VIS-NIR spectroscopy. Proc. SPIE Photonics Europe: Optical Sensing and Detection, SPIE, Brussels, 2010, 7726, 7726D-1-7726D-12.

25. Keppler, H. Crystal field spectra and geochemistry of transition metal ions in silicate melts and glasses. Am. Miner., 1992, 77, 62-75.

26. Colomban, Ph., Tournié, A. \& Ricciardi, P. Raman spectroscopy of copper nanoparticle-containing glass matrices: ancient red stainedglass windows. J. Raman Spectrosc., 2009, 40, 1949-55.

27. Freestone, I. C. The provenance of ancient glass through compositional analysis. Mater. Res. Soc. Symp. Proc., 2005, 852, OO8.1.1-OO8.1.14

28. Freestone, I. C., Ponting, M. \& Hughes, M. J. The origins of Byzantine glass from Maroni Petrera, Cyprus. Archaeometry, 2002, 44, 257-72.

29. Ceglia, A., Cosyns, P., Nys, K., Terryn, H., Thienpont, H. \& Meulebroeck, W. Late antique glass distribution and consumption in Cyprus: a chemical study. J. Archaeol. Sci., 2015, 61, 213-22.

30. Shortland, A. J. Analysis of first millennium BC glass vessels and beads from the Pichvnari Necropolis, Georgia. Archaeometry, 2009, 51, 947-65.

31. Silvestri, A., Molin, G. \& Salviulo, G. The colourless glass of Iulia Felix. J. Archaeol. Sci., 2008, 35, 331-41.

32. Freestone, I. C. Chemical analysis of ' raw' glass fragments. Excavations at Carthage, The Circular Harbour, North Side, Oxford Univ. Press for British Academy, 1994, Vol. II (1), 290.

33. Verità, M. Le analisi dei vetri. Le verre de l'Antiquité tardive et du Haut Moyen Âge (IVe-VIIIe), typologie, chronologie, diffusion, Musée Archéologique Départemental du Val d'Oise, Guiry-en-Vexin, 1995, 291-300.

34. Foy, D., Picon, M., Vichy, M. \& Thirion-Merle, V. Caractérisation des verres de la fin de l'Antiquité en Méditerranée occidentale: l'émergence de nouveaux courants commerciaux. Échanges et commerce du verre dans le monde antique: actes du colloque de l'Association Française pour l'Archéologie du Verre. Aix-en-Provence et Marseille, 7-9 juin 2001. Editions Monique Mergoil, Montagnac, France, 2003, 41-85.

35. Mirti, P., Ferrari, R.P., Laurenti, E. \& Casoli, A. A study of Roman glass by reflectance and electron paramagnetic spectroscopy. Spectrochim. Acta A, 1993, 49, 1361-71.

36. Arletti, R., Vezzalini, G., Biaggio, S. \& Maselli Scotti, F. Archaeometrical studies of Roman Imperial Age glass from Canton Ticino. Archaeometry, 2008, 50, 606-26.

37. Sayre, E. V. \& Smith, R. W. Compositional Categories of Ancient Glass.

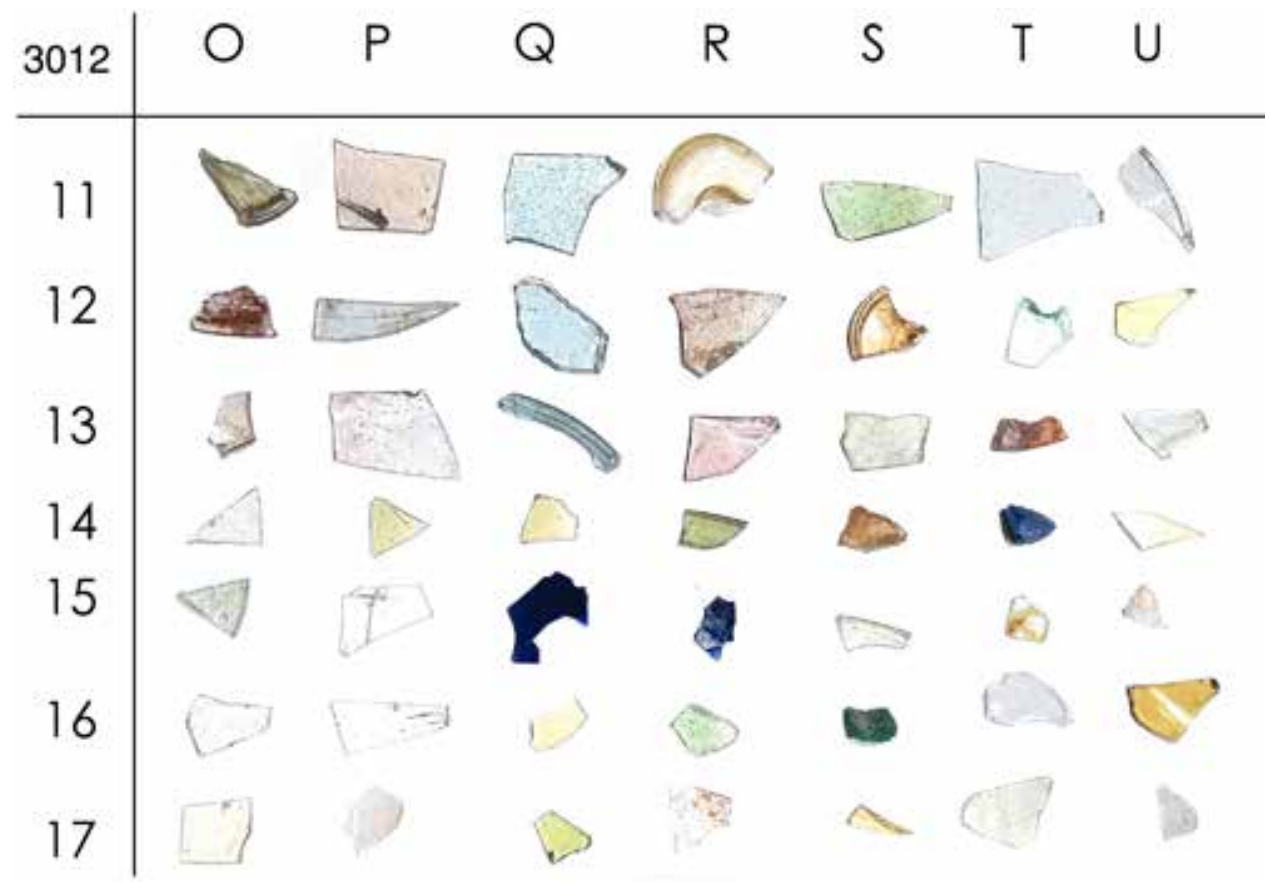

Figure S1. Overall image of fragments from SU 3012 [Colour available online] 
Science, 1961, 133, 1824-6.

38. Lilyquist, C.\& Brill, R. H. Studies in ancient Egyptian glass. Metropolitan Museum of Art, New York, 1995.

39. Mass, J. L., Wypyski, M. T., Stone, R. E. Malkata and Lisht glassmaking technologies: towards a specific link between second millennium BC metallurgists and glassmakers. Archaeometry, 2002, 44, 67-82.

40. Shugar, A. N. Byzantine opaque red glass tesserae from Belt Shean, Israel. Archaeometry, 2000, 42, 375-84.

41. Padovani, S., Sada, C., Mazzoldi, P., Brunetti, B., Borgia, I., Sgamellotti, A., Giulivi, A., D' Acapito, F. \& Battaglin, G. Copper in glazes of Renaissance luster pottery: nanoparticles, ions, and local environment. J. Appl. Phys., 2003, 93, 10058-63.

42. Arletti, R., Dalconi, M. C., Quartieri, S., Triscari, M. \& Vezzalini, G.

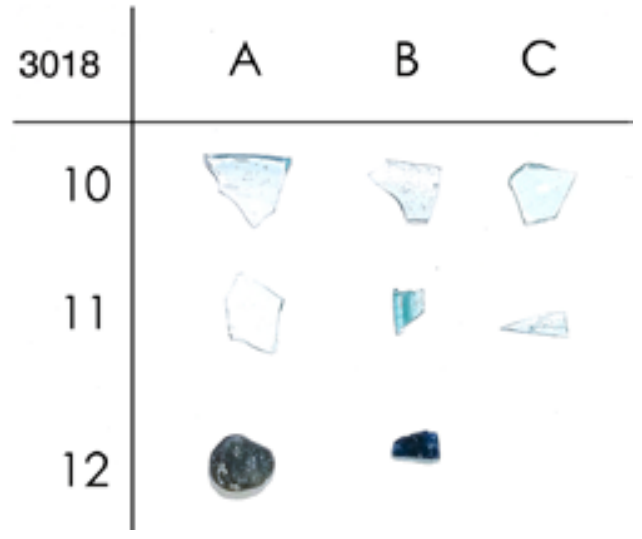

Figure S2. Overall image of fragments from SU 3018 [Colour available online]

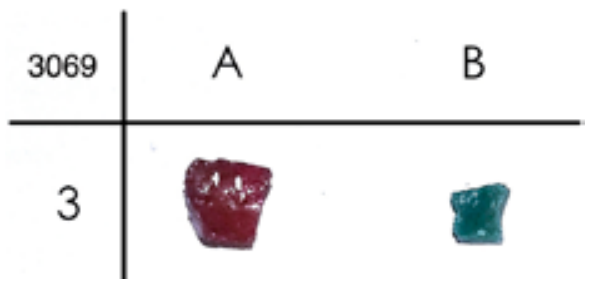

Figure S5. Overall image of fragments from SU 3069 [Colour available online]
Roman coloured and opaque glass: a chemical and spectroscopic study Appl. Phys. A, 2006, 83, 239-45.

43. Shortland, A. J. The use and origin of antimonate colorants in Early Egyptian Glass. Archaeometry, 2002, 44, 517-30.

44. Arletti, R., Fiori, C. \& Vandini, M. A study of glass tesserae from mosaics in the monasteries of Daphni and Hosios Loukas (Greece). Archaeometry, 2010, 52, 796-815.

45. Galli, S., Mastelloni, M., Ponterio, R., Sabatino, G. \& Triscari, M. Raman and scanning electron microscopy and energy dispersive $x$-ray techniques for the characterization of colouring and opaquening agents in Roman mosaic glass tesserae. J. Raman Spectrosc., 2004, 35, 622-7.

46. Stiaffini, D., Il vetro nel Medioevo. Tecniche Strutture Manufatti, Palombi Editori, Roma, 1999.

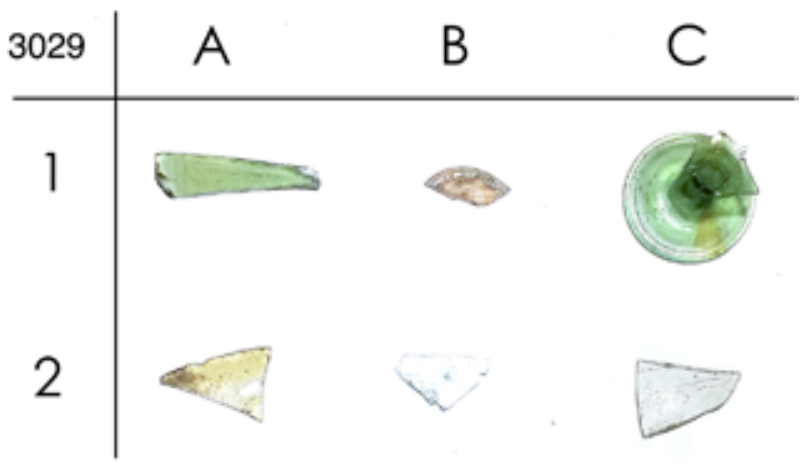

Figure S3. Overall image of fragments from SU 3029 [Colour available online]

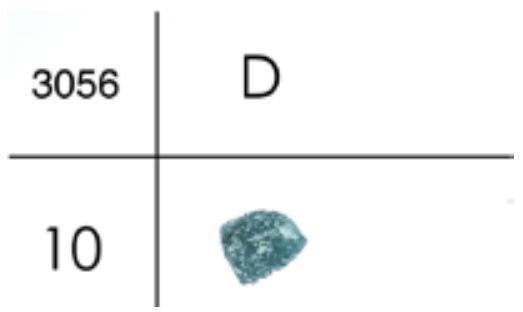

Figure S4. Overall image of fragments from SU 3056 [Colour available online]

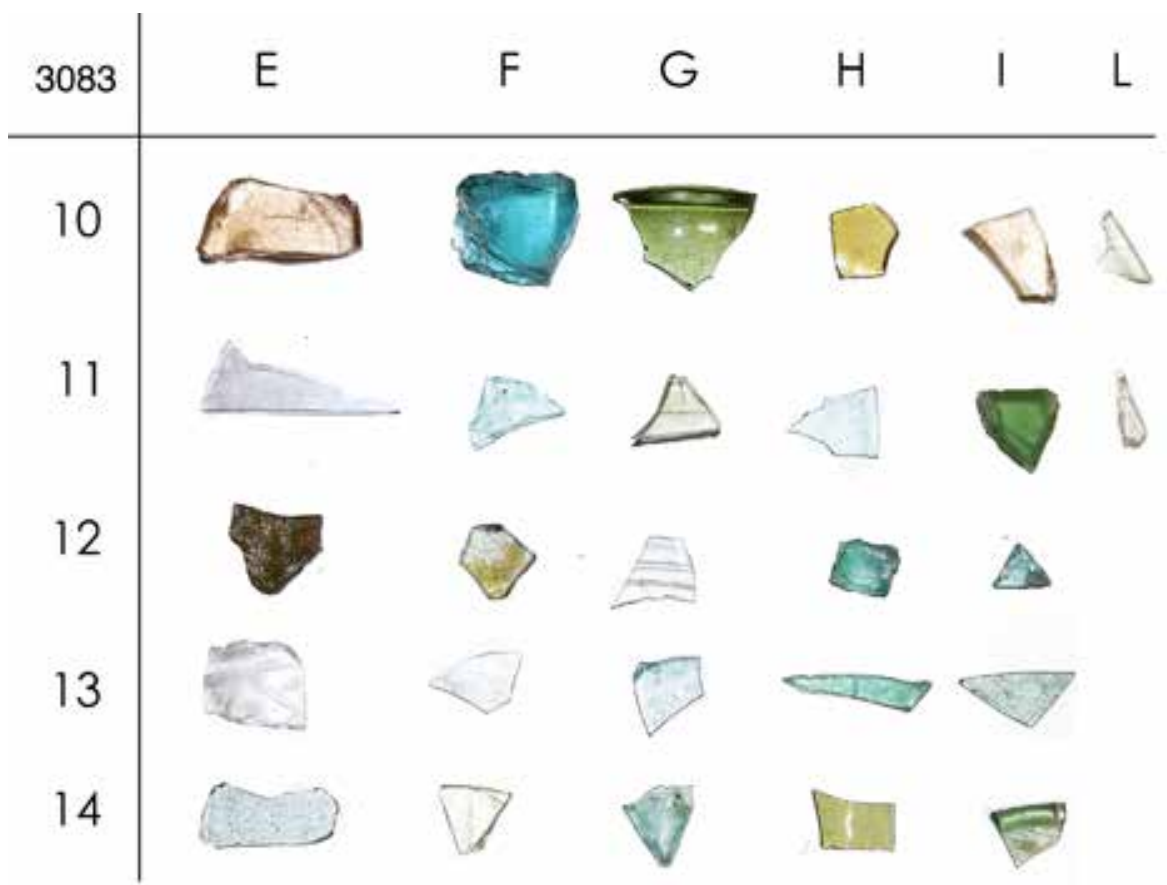

Figure S6. Overall image of fragments from SU 3083 [Colour available online]

12 Glass Technology: European Journal of Glass Science and Technology Part A Volume 61 Number 1 February 2020 


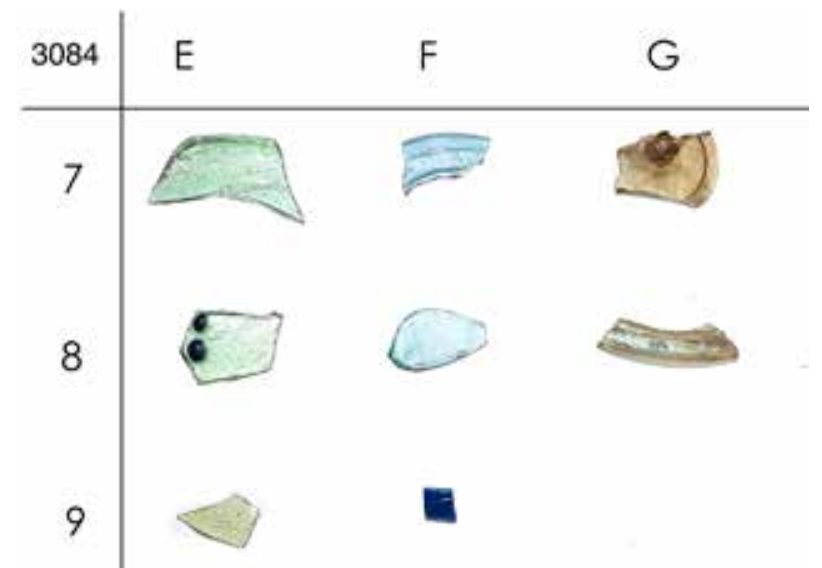

Figure S7. Overall image of fragments from SU 3084 [Colour available online]

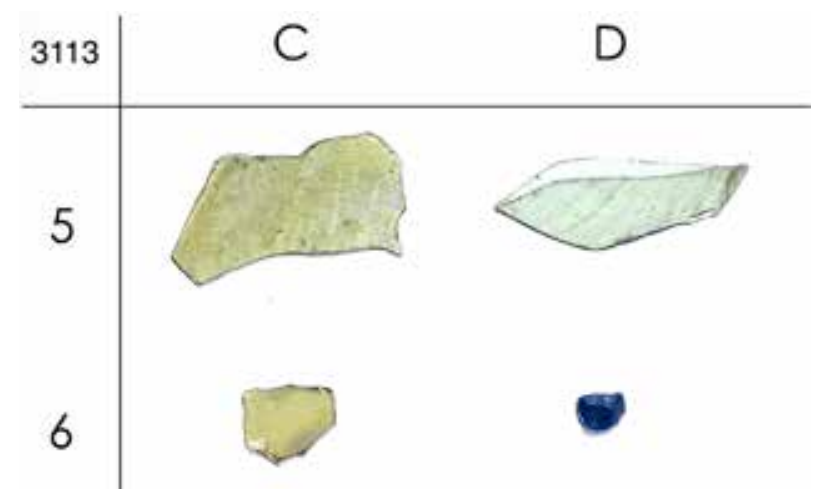

Figure S8. Overall image of fragments from SU 3113 [Colour available online]

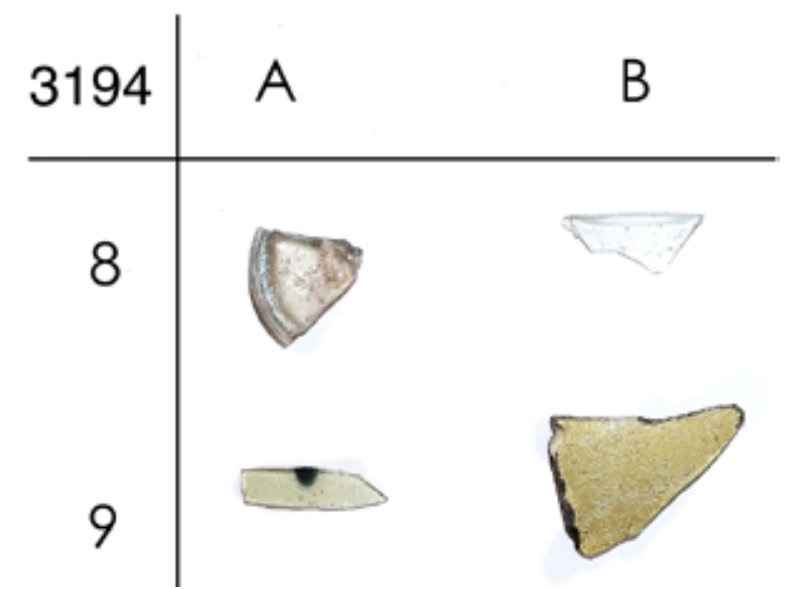

Figure S9. Overall image of fragments from SU 3194 [Colour available online]

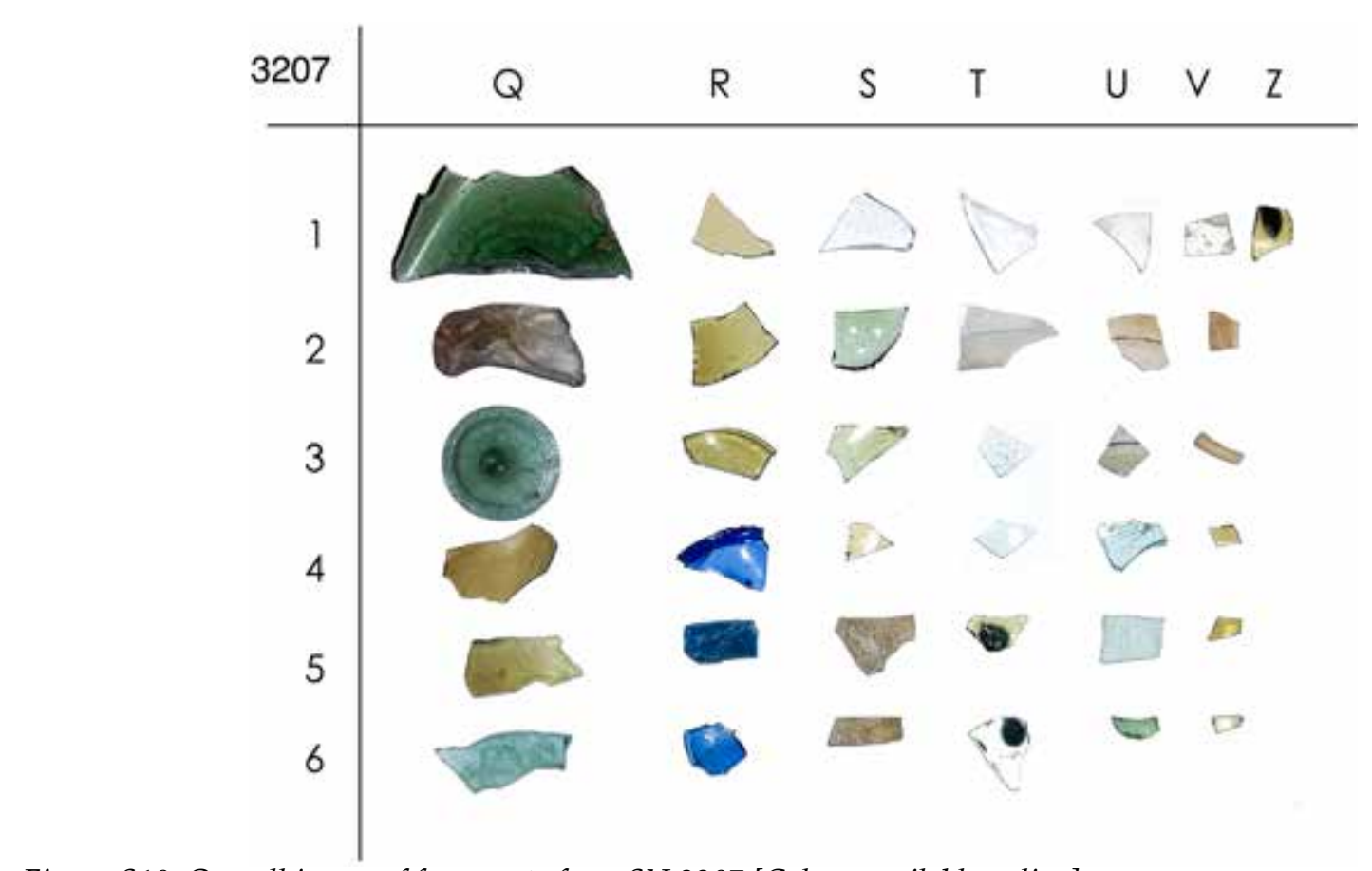

Figure S10. Overall image of fragments from SU 3207 [Colour available online] 


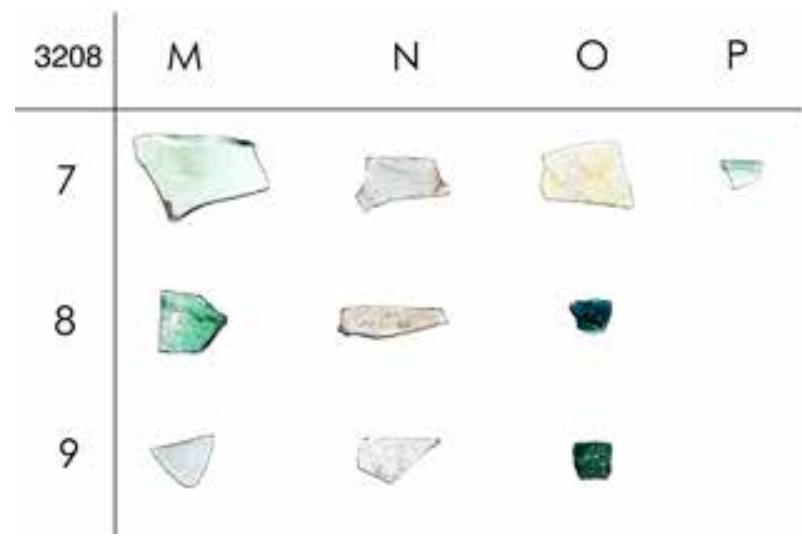

Figure S11. Overall image of fragments from SU 3208 [Colour available online]

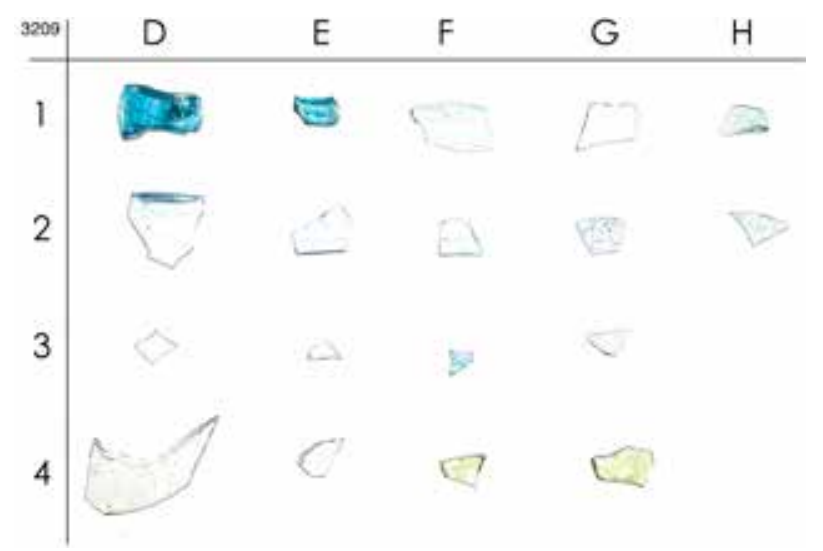

Figure S12. Overall image of fragments from SU 3209 [Colour available online]

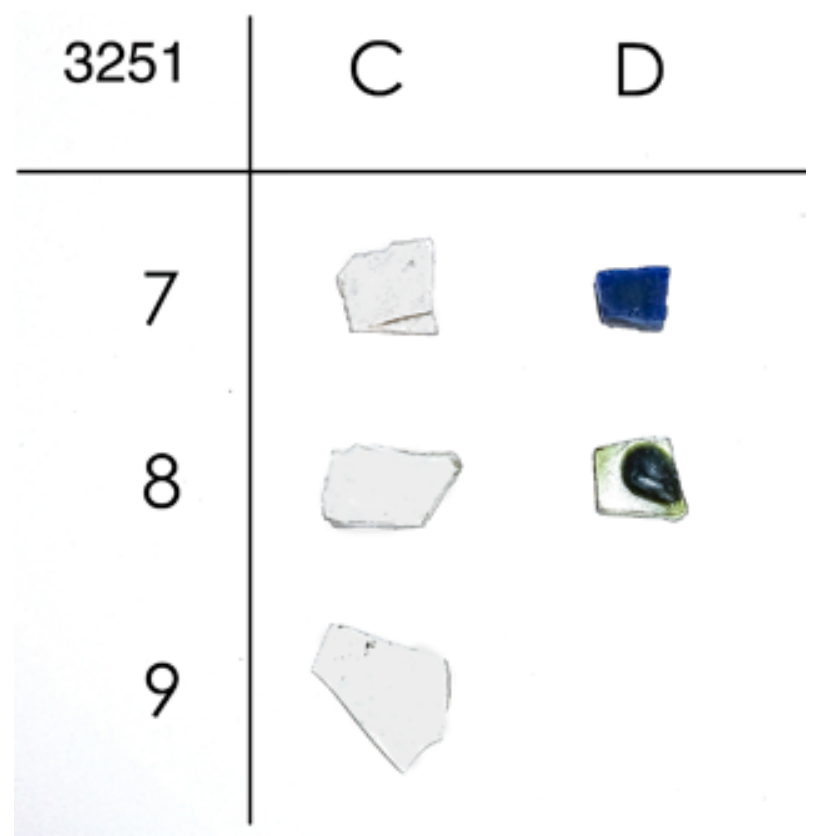

Figure S15. Overall image of fragments from SU 3251 [Colour available online]

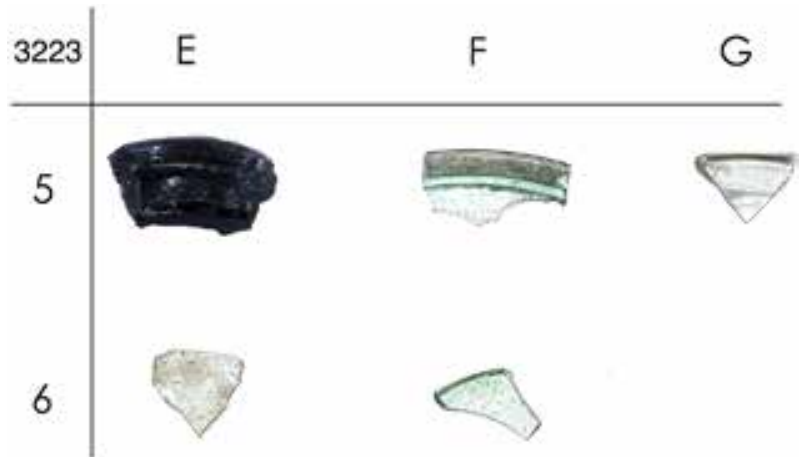

Figure S13. Overall image of fragments from SU 3223 [Colour available online]

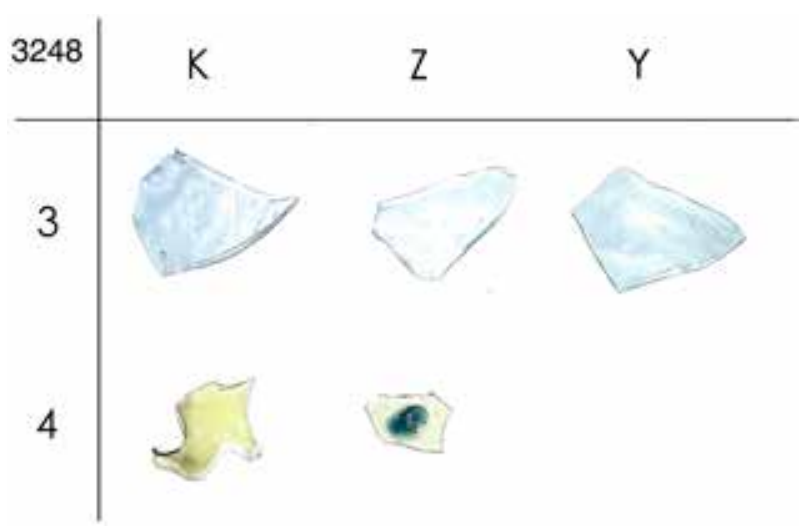

Figure S14. Overall image of fragments from SU 3248 [Colour available online]

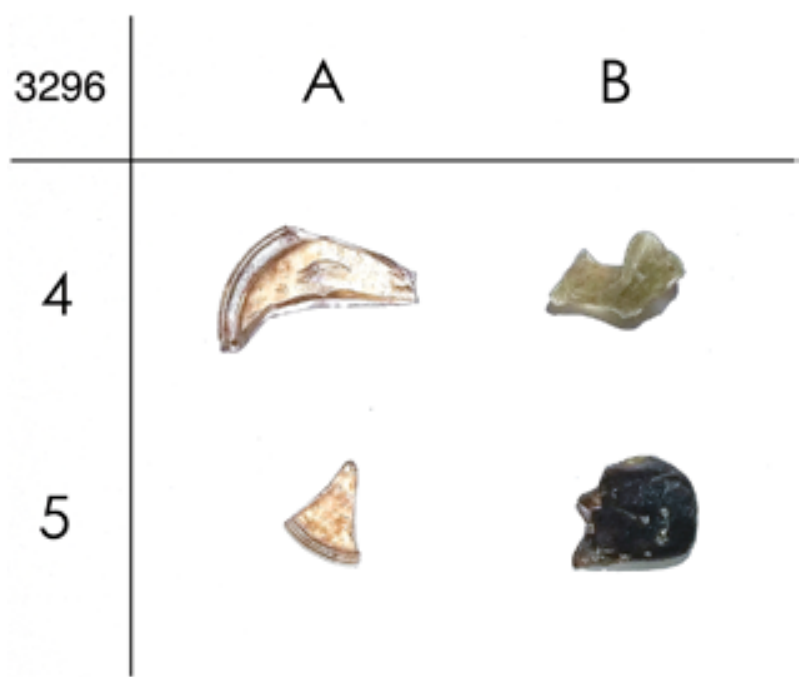

Figure S16. Overall image of fragments from SU 3296 [Colour available online] 


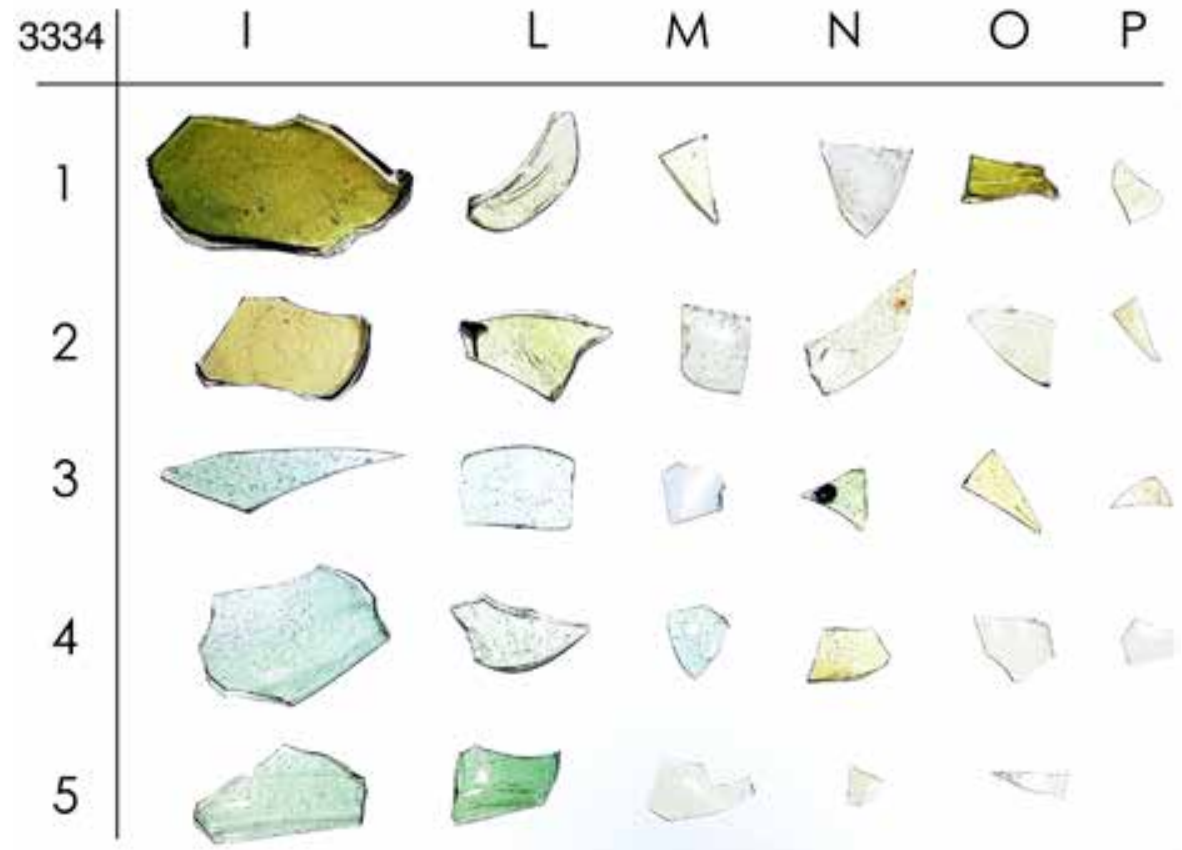

Figure S17. Overall image of fragments from SU 3334 [Colour available online]
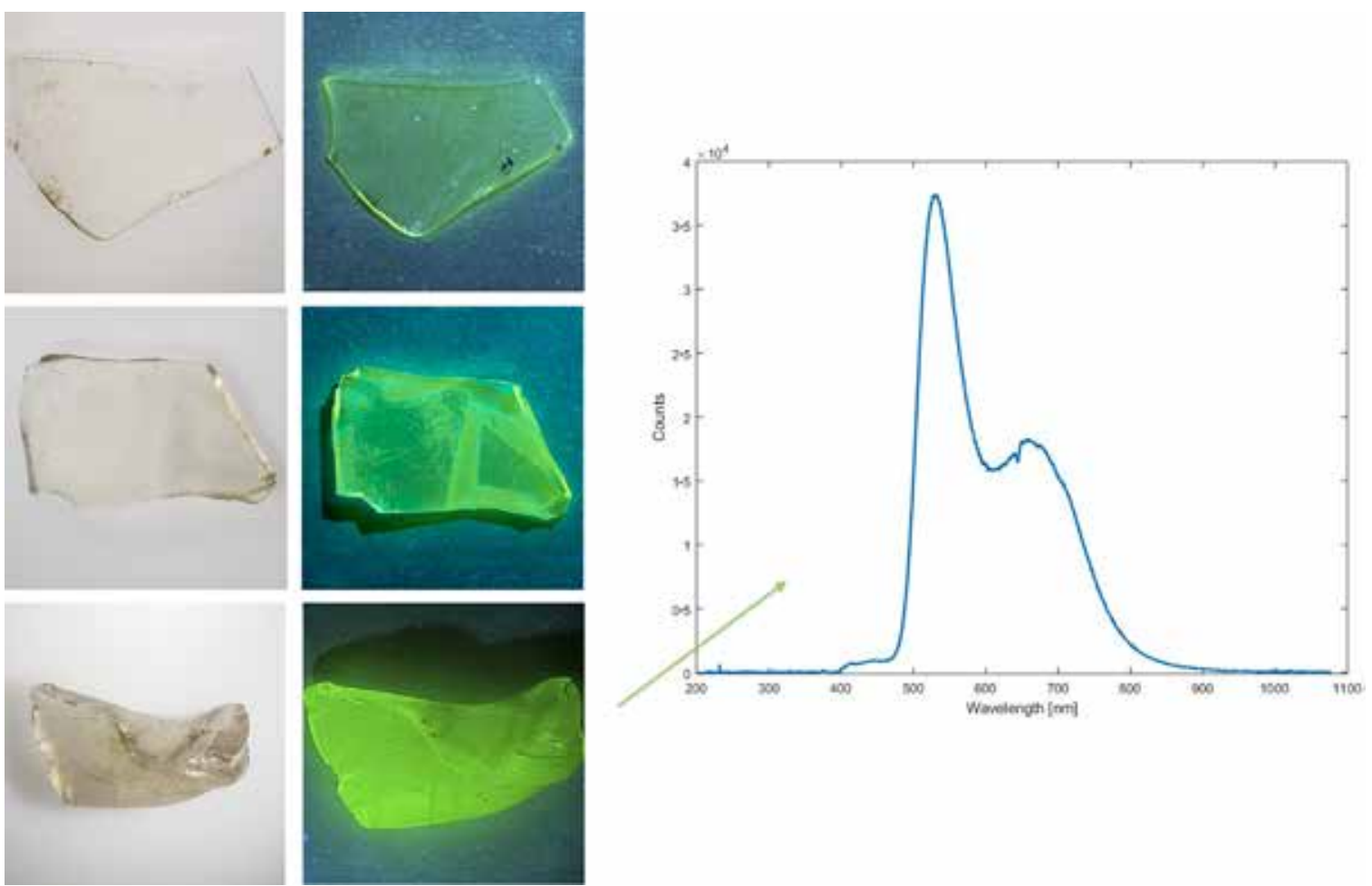

Figure S18. VIS and UV-light (365 $\mathrm{nm}$ ) images of fluorescent glass samples and LIF spectrum of fragment Q2 (SU 3207) [Colour available online] 